\title{
DIFFERENTIAL EFFECTS OF UNILATERAL LESIONS ON LANGUAGE PRODUCTION IN CHILDREN AND ADULTS
}

\author{
Elizabeth Bates \\ University of California, San Diego \\ Judy Reilly \\ San Diego State University \\ Beverly Wulfeck \\ San Diego State University \\ and University of California, San Diego \\ Nina Dronkers \\ VA Northern California Health System, Audiology \& Speech Pathology \\ Meiti Opie \\ University of California, San Diego \\ Judi Fenson, Sarah Kriz and Rita Jeffries \\ San Diego State University \\ LaRae Miller and Kathryn Herbst \\ University of California, San Diego
}

Please address all correspondence to Elizabeth Bates, Center for Research in Language 0526, University of California, San Diego, La Jolla, CA 92093-0526 - bates@crl.ucsd.edu, Phone: 858-534-3007/6070, Fax: 858-534-6788.

Brain and Language, 2001, 79(2), 223-265. 


\title{
Differential Effects of Unilateral Lesions on Language Production in Children and Adults
}

\begin{abstract}
We present the first direct comparison of language production in brain-injured children and adults, using agecorrected $z$ scores for multiple lexical and grammatical measures. Spontaneous speech samples were elicited in a structured biographical interview from 38 children (5-8 years of age), 24 with congenital left-hemisphere damage (LHD) and 14 with congenital right-hemisphere damage (RHD), compared with 38 age- and gender-matched controls, 21 adults with unilateral injuries (14 LHD, 7 RHD), and 12 adult controls. Adults with LHD showed severe and contrasting profiles of impairment across all measures (including classic differences between fluent and nonfluent aphasia). Adults with RHD (and three nonaphasic adults with LHD) showed fluent but disinhibited and sometimes empty speech. None of these qualitative or quantitative deviations were observed in children with unilateral brain injury, who were in the normal range for their age on all measures. There were no significant differences between children with LHD and RHD on any measure. When LHD children were compared directly with LHD adults using age-corrected $z$ scores, the children scored far better than their adult counterparts on structural measures. These results provide the first systematic confirmation of differential free-speech outcomes in children and adults, and offer strong evidence for neural and behavioral plasticity following early brain damage.
\end{abstract}

For more than 3000 years, we have known that language production can be damaged or lost following brain injury (O'Neill, 1980), and since the 1860's we have also known that language deficits are overwhelmingly more likely if the injury involves the left side of the brain (Cotard, 1868, cited in Woods \& Teuber, 1978; Bernhardt, 1897). To account for these longstanding and well-documented facts, it seems reasonable to hypothesize that the left side of the human brain contains some kind of specialized organ for language and speech (Fodor, 1983; Newmeyer, 1997; Pinker, 1994; Rice, 1996), one that should be observable in its approximate adult form at birth, not unlike the liver or the heart. This hypothesis is buttressed by studies showing that adult-like structural asymmetries between the left and right sides of the brain are evident at and before birth (Witelson \& Pallie, 1973), and by electrophysiological studies showing that the left side of the brain is significantly more active in response to complex auditory stimuli (including speech) in the human infant (Molfese \& Segalowitz, 1988).

In view of all these facts, it is difficult to understand why adults and children who acquired unilateral brain injuries early in life perform so well on language tasks (Bates, 1999; Bates, Vicari, \& Trauner, 1999; Eisele \& Aram, 1995; Elman et al., 1996; Feldman, Holland, Kemp, \& Janosky, 1992; Nass, in press; Stiles, Bates, Thal, Trauner, \& Reilly, 1998; Vargha-Khadem, Isaacs, \& Muter, 1994; Vicari et al., 2000). In fact, in the absence of confounding factors (e.g., intractable seizures-Vargha-Khadem, Isaacs, van der Werf, Robb, \& Wilson, 1992), children with early left-hemisphere injuries almost always go on to acquire language abilities within the normal or low-normal range. Even more surprising from the point of view of adult aphasia, it has proven extremely difficult to demonstrate significant differences in language outcomes between children with left-hemisphere damage (LHD) vs right-hemisphere damage (RHD). Although some differences have been reported during the period in which language is first acquired (Bates et al., 1997; Reilly, Bates, \& Marchman, 1998; Thal et al., 1991; Vicari et al., 2000), the vast majority of studies have failed to uncover robust and statistically reliable left/right differences in children who are tested beyond 5-7 years of age. To be sure, a few studies have reported subtle differences between LHD children and their controls, differences that are not observed (or occur in a less specific form) when RHD children are compared to their own, separate group of controls (Aram, Ekelman, \& Whitaker, 1985; Aram, Ekelman, Rose, \& Whitaker, 1985; Ballantyne, Scarvie, \& Trauner, 1994-but see Ballantyne \& Trauner, 1999; Dennis \& Whitaker, 1976, 1977; Riva \& Cazzaniga, 1986; Riva, Cazzaniga, Pantaleoni, Milani, \& Fedrizzi, 1986). However, as Bishop has pointed out in some insightful methodological reviews (Bishop, 1983, 1997; see also Bates, 1999; Bates \& Roe, 2001), those studies that have uncovered hemispheric differences are plagued by methodological limitations, including mixed etiologies and age of onset, small sample size, and the absence of direct comparisons between LHD and RHD children in a single statistical design. In studies using larger and more balanced samples, with a direct comparison between LHD and RHD children, the predicted hemispheric difference in language outcomes is absent by the time children are in elementary school.

Why are language outcomes so different in children and adults with comparable injuries? Part of the answer lies in the extraordinary neural and behavioral plasticity observed in the developing brain (Deacon, 1997; Elman et al., 1996; Johnson, 1997; Quartz \& Sejnowski, 1994, 1997), a phenomenon that has been amply documented in animal studies in which the same lesions are delivered in the same way while systematically varying age of lesion onset (Kennard, 1936; Kolb, 1999; Kolb \& Whishaw, 1998; Stein, 1988; Webster, Bachevalier, \& Ungerleider, 1995). Further- 
more, current evidence suggests that the gradual loss or reduction in plasticity later in life results at least in part from experience itself, after a skill has been learned, practiced and overlearned for many years (or, in the case of human adults with acquired aphasia, for many decades), and its neural substrates are consolidated, even sculpted, into a form that precludes starting all over again (Elman et al., 1996; Kuhl, 1993; Kuhl, Williams, Lacerda, Stevens, \& Lindblom, 1992; Marchman, 1993).

All of this may seem obvious at this point in the history of neuropsychological research, except for one problem: conclusions regarding differential language outcomes in children and adults are based almost entirely on clinical experience, and/or on informal meta-analyses across studies in which widely different methods were used with the respective child and adult populations. Both our conclusions and our explanations for them would be on firmer ground if they were based on systematic comparisons of brain-injured children and adults on the same language outcome measures. Of course such studies must take into account the fact that language continues to develop across the lifespan in normal children and adults (Bates, Thal, Finlay, \& Clancy, in press; Marchman, Bates, Burkhardt, \& Good, 1991), and therefore constitutes a moving target. In order to compare adults and children on the same language outcome measures, patients with left- and right-hemisphere damage must be compared with their expected level of development taken into account. In the intelligence-testing tradition, this is done by basing calculations of IQ on mental age. In language research, individual child and adult patients can be given $z$ scores on each potential language measure, based on performance by their age-matched normal controls.

We are aware of only two studies that have taken this approach, both of them devoted to the study of auditory sentence comprehension. Kempler, van Lancker, Marchman, and Bates, (1999) compared adults with RHD and LHD to a sample of 6- to 12-yearold children who had suffered comparable injuries (also due to cerebrovascular accidents or CVA) during the pre-/perinatal period. Child and adult patients with LHD vs RHD were compared directly in an age-byside-of-lesion design, using age-based $z$ scores derived from relatively large samples of age-matched controls on the van Lancker and Kempler Familiar Phrases Test. Adult patients displayed the now-familiar double dissociation between idiomatic or familiar phrases (more impaired in patients with RHD) and novel phrases matched for length and complexity (more impaired in patients with LHD). Child patients displayed absolutely no evidence for a double dissociation; children with LHD vs RHD both performed significantly below normal controls as a group, but did not differ significantly from each other. Even more important, the child patients performed within the low-normal range on both measures, while the adult patients performed many standard deviations below their age-matched controls on their weakest measure (i.e., novel phrases for patients with LHD; familiar phrases for patients with RHD). In other words, the children were not significantly impaired (i.e., their performance did not reach criteria required to establish the existence of a language deficit) following either right- or left-hemisphere damage, and no selective effects of lesion side were detected.

More recently, Dick et al. (1999) have compared performance by children and adults with unilateral brain injury and their age-matched controls in an online auditory sentence comprehension test that contrasts syntactically simple sentences (active and subject clefts that follow canonical word order) with syntactically complex sentences (passives and object clefts that violate canonical word order). All sentences were fully grammatical, and semantically reversible. All groups (including normal controls) displayed the same basic profile of lower accuracy on noncanonical sentences (object clefts and passives). Among the children, group by sentence type interactions were obtained indicating that (1) the youngest normal children were at a greater disadvantage than older children on the more difficult noncanonical sentence types; (2) as a group, braininjured children showed a greater disadvantage on the difficult sentences than their age-matched controls; (3) however, the brain-injured children were still within the normal range for their age; and most important for our purposes here, (4) there were no significant differences between children with LHD and children with RHD on any of the sentence types. In contrast with these findings for children, adults with unilateral brain injury were severely impaired, especially on the noncanonical sentences. Direct comparisons of adults and children with LHD clearly demonstrate that LHD is associated with receptive agrammatism in adults but not in children.

These two studies of sentence comprehension constitute the first direct and systematic comparisons of child and adult patients on the same language outcome measures. They provide further support for the conclusion that the same lesions produce different outcomes in children and adults. However, both studies were based on a simple discriminant response (finding the picture that matches the sentence, measured off-line of three options in Kempler et al., measured on-line of two options in Dick et al.). Hence they provide no qualitative information about the nature of the linguistic "sparing" observed in brain-injured children, nor is it possible to compare the symptoms of child and adult patients in any detail. Furthermore, as has been the case in many recent studies of sentence comprehension in aphasia (Bates, 1991; Caplan \& Hildebrandt, 1988), these two studies provide little evidence for differential patterns of comprehension breakdown across subgroups of adult aphasics, e.g., no systematic differences between patients with Broca's aphasia, Wernicke's 
aphasia, or milder aphasic syndromes. Much more could be learned if comparative data could be obtained on free-speech measures that yield rich and detailed information not only about the presence of a language deficit, but about the variety of symptoms that can be observed in different forms of aphasia in adults. Such data could be used to further test the hypothesis that language outcomes differ in children and adults with unilateral injury, and it might also yield new information about the different strategies that children and adults develop to deal with their injuries.

In this article, we present what is (to the best of our knowledge) the first direct and systematic compari-son of language production in brain-injured children and adults, based on a structured biographical interview to (with adaptations appropriate for the patients' age levels). This study will provide further evidence for differential outcomes in children and adults of the sort that we have just reviewed. However, it will also place the performance observed in brain-injured children against a rich landscape of qualitative information about the contrasting forms of language impairment that can be observed in adults with different forms of aphasia.

\section{METHOD}

\section{Participants}

Participants included 38 children with early unilateral brain injury (24 with left-hemisphere damage, or LHD; 14 with right-hemisphere damage, or RHD) and 38 age- and gender-matched controls. All children were between 5-8 years of age at time of testing. All child patients had congenital injuries (prior to six months of age) to one side of the brain, a single contiguous lesion (although very large in many cases) confirmed through CT or MRI (See Table 1 for details). In most cases, the scans were directly available to the authors; in rare cases, classifications were made based on radiological reports (these cases are indicated in Table 1 by "n.a.", indicating that detailed intrahemispheric information is not available).

Although it is not always possible to determine the etiology of congenital lesions, the great majority of these injuries are due to pre- or perinatal stroke, which come to the neurologist's attention because of seizures and/or perceived weakness on one side of the body. No cases of lesions due to tumor, trauma or arteriovenous malformations were included in the study, although one child had undergone surgery for shunting. Children were also excluded from the sample if they had additional medical conditions (other than seizure history) that would complicate interpretation of the effects of lesions on language outcomes, and all children had corrected or uncorrected vision and hearing within the normal range. We did not use IQ criteria to exclude child patients, nor were children matched to controls on IQ. Most studies of verbal and nonverbal IQ in this population (including our own-Ballantyne \& Trauner, 1994, 1999; Bates et al., 1999; Bates \& Roe, 2001) report mean IQs between 90 and 95 in children with congenital lesions, although there are typically two to three times more cases with borderline IQs or moderate mental retardation (i.e., IQs below 80) than we would expect by chance if children were drawn from the normal population. If focal lesion children as a group perform below controls (and as we shall see, this is rarely the case in the present study), then it is possible that mental age differences are responsible for the effect. Table 1 summarizes demographic and neurological information for the 38 child patients).

Adult participants included 14 patients with LHD, 7 patients with RHD, and 12 controls in the same range of age and social class. All brain-injured patients were tested more than 6 months after lesion onset, and were screened to exclude cases with dementia and/or uncorrectable vision or hearing problems. All adult lesions were due to cerebrovascular incidents to one side of the brain, confirmed by CT or MRI. No cases of lesions due to trauma, tumor or arteriovenous malformation were included in the study. The 14 adult patients with LHD were tested on the Western Aphasia Battery, which yielded the following classifications: three patients with Broca's aphasia, 3 with Wernicke's aphasia, 5 with anomia, and 3 patients who did not meet criteria for aphasia (performing above threshold on all WAB subscales). Table 2 summarizes demographic and neurological information for the 21 patients with LHD or RHD.

One methodological issue must be noted regarding selection of LHD patients. In the child population, we recruited all children who met our criteria, with no presumptions regarding the presence or nature of a language disorder. In the adult population, this is a much more complex matter. It is common practice to administer aphasia batteries to any patient who is at risk for aphasia, either because of the nature of the stroke or because of symptoms that become apparent soon thereafter. Patients who receive a diagnosis of aphasia tend to be available for research because of their continued presence in rehabilitation centers and other out-patient clinics. Patients who are symptom free following a lefthemisphere lesion are much more difficult to find. This means, of course, that there is a confound built into our adult-child comparisons in the case of LHD: The child population represents all available cases, while the adult population may be biased towards patients with aphasia. The ideal solution to this dilemma would be to select patients randomly from stroke registries, a solution that was not available to us for the purposes of this study. We therefore attempted to construct a representative population of patients with LHD, reflecting numerically the range of outcomes that are likely to be observed following LHD, in numbers that approximate the probability of aphasia following a serious lefthemisphere stroke within this target age range. Hence 
the more severe patients (Broca's and Wernicke's) were fewer in number (three per group), the patients with simple anomia (the final state for many patients who recover from more serious aphasias) were somewhat more numerous (a total of five), and we also recruited three patients with LHD who did not result in clinically significant aphasia. Although we would like to underscore that our findings should be replicated with large, unselected samples of LHD and RHD patients drawn from stroke registries, ample experience with LHD stroke victims in our laboratory and others around Europe and the U.S. suggests to us that we have indeed obtained a representative sample of stroke outcomes in adult patients.

\section{Materials and Procedure}

All patients and controls were videotaped during a structured biographical interview focusing on family history, work or school, hobbies, and recent events, administered one-on-one in a quiet room (usually in a laboratory setting, although home visits were conducted for some adult patients). The interviews were separately tailored to respect the interests of 5-8-year-old children vs adults. The list of questions and open-ended probes used for the respective child and adult populations is summarized in Appendices A and B.

All videotapes were transcribed according to the conventions of the Child Language Data Exchange System (MacWhinney \& Snow, 1985). The children's transcripts were coded initially with the minimal ("minchat") codes and then expanded to the full "CHAT" coding which includes morpheme-by-morpheme glosses and marking for errors. Adults transcripts were coded in the minchat format, but error codes and morpheme codings to permit calculations of mean length of utterance in morphemes were added later. Transcribers went through a lengthy period of training, and adequate interrater reliabilities were assured prior to transcription and coding.

The resulting transcripts were coded in two successive stages. At the first stage, the CLAN program was used to extract automatically information about numbers of word tokens and types, type/token ratios, number of morphemes, and mean length of utterance in morphemes. Results for total amount and length of speech output are based on this stage in coding. It became apparent early in this process that many of the adult patients (including nonaphasic patients with LHD and patients with RHD) produced higher than normal amounts of speech output in this situation, far beyond the 50-100 utterances usually required for detailed freespeech coding. We therefore restricted the second phase of coding to the first 100 utterances for each participant (which included all utterances for participants who produced fewer than 100 utterances).

At the second stage of coding, transcripts were analyzed independently by two or more coders (with discrepancies resolved through discussion). All utterances containing unintelligible material were eliminated at this level of coding, and repetitions, false starts and self-corrections were also removed from consideration. The resulting material was then coded along the following dimensions: (1) number of propositions (defined in terms of tensed or untensed verbs); (2) a division of sentences into complete sentences with all obligatory arguments (simple or complex) vs fragmented sentences missing obligatory material due to discourse-appropriate ellipsis in response to a question or previous comment (frank omission errors were not included in this category); (4) a count of complex syntactic types and tokens; and (5) separate counts for morphological errors (overgeneralizations, omissions, substitutions), lexical errors (neologisms or nonwords; incorrect word substitutions or additions), and omissions (keeping in mind that it is not always possible to determine the identity of the missing content of function words, omissions were counted as whole events, with no attempt to count the number of elements that should have been provided at that point in the sentence). Appendix $\mathrm{C}$ contains a list of the structures that were counted as complex syntactic types or tokens, with an emphasis on phrasal elaboration and embedding, various kinds of noun and verb complements, coordination, and subordination. Appendix D contains a description of the coding scheme used to identify morphological, lexical, and omission errors. Interrater reliabilities were determined to assure that coders had acceptable levels of agreement in the application of the coding schemes at these two levels of analysis.

\section{RESULTS \& DISCUSSION}

The good news and bad news about free-speech analysis is that it yields a large number of distinct but interrelated dependent variables, which means that there is a great deal of information to report. Because we will describe results of multiple analyses in the section below, we have tried to make the reader's job easier by placing the details of all statistical analyses in tables, so that the text can be devoted to a relatively uncluttered summary of significant findings. The only exceptions will be a small number of multivariate analyses that require a different reporting format, and are handled directly in the text.

We will begin with a description of the amount of speech produced (in total utterances, word tokens, word types, and morphemes) together with a common measure of average utterance length (mean length of utterance in morphemes, or MLU). This is followed by a discussion of propositional and syntactic complexity (based on no more than 100 utterances for each participant), ending with results of error analyses (total errors, omissions, morphological and lexical errors). Detailed results (means and standard errors) are summarized for each subgroup in Table 3, for all measures (raw scores and/or proportion scores, with $z$ score variants of both). Results for children are broken into three subgroups: normal controls, LHD and RHD. Results for adults are summarized in the same three 
categories (normal controls, LHD and RHD), and then the LHD cases are broken down further by aphasia type (Broca's, Wernicke's, anomics, and nonaphasic patients with LHD). The same format is also followed in all figures.

A common plan of analysis for comparing children and adults is followed for all key variables throughout the article. Separate $2 \times 3$ univariate Age (Child vs Adult) by Lesion (Normal, LHD, RHD) analyses of variance were conducted for each dependent variable, as well as separate one-way analyses over lesion group within children and adults, respectively. Post hoc tests were also applied (two-tailed t-tests) to clarify which pairs of subgroup contrasts are contributing to the effects that emerge from analyses of variance (e.g., lesion group comparisons within age levels; adult/child comparisons within each lesion group). Details for each analysis (degrees of freedom, $F$ and $t$ values, significance levels) are presented in tables (Table 4 for amount of speech; Table 5 for complexity analyses; Table 6 for error analyses). In Tables 4-6, we have included the actual value for any alpha level at $p<.20$ or less, so that readers who are interested in nonsignificant trends by 2 -tailed tests, which would constitute $p<.10$ by one-tailed tests, are free to consider alternative interpretations. (All $p$ values listed as "n.s." are at p > .20.)

\section{Collapsing over Age Levels for Child Participants}

Before proceeding, we note that all scores for children were initially analyzed to assess the contribution of developmental changes within the 5- to 8-year range. Age (5, 6, 7 and 8 years) $\times$ Lesion (normal, LHD, and RHD) analyses of variance were conducted, for children only, on the main variables of interest across all categories (number of utterances, word tokens, word types, word tokens, and morphemes; mean length of utterance in morphemes; number of propositions; number of syntactically complex tokens and types and percentage of sentences that were elliptical fragments; total errors, omission errors, morphological errors, lexical errors, and a specific analysis of number of morphological overregularizations). There were no main effects of age and no age by lesion group interactions in analyses of amount of speech produced. On analyses of propositional and syntactic complexity, there were also no interactions between age (from 5-8 years) and lesion group (normal, LHD, and RHD), but we did find main effects of age on two measures: ratio of propositions per utterance and ratio of fragmentary (elliptical) sentences to all sentences produced. Examination of cell means indicated that these two main effects of age are not monotonic, that is, it is not the case that propositional complexity goes up and fragmentation goes down with age as we might expect. Instead, we found a small but significant increase in the production of fragmentary utterances and a small but significant nonlinear drop around age 7 in ratio of proportions per utterance. These results do not mean that children are getting worse with age! Rather, as a reading of the transcripts makes clear to anyone familiar with child language, these results reflect a developmental shift in discourse strategies from the kind of independent rambling that is sometimes observed in young children (who sometimes "go off on tangents" in response to the interviewer's questions) to a more passive but also more cooperative approach to conversation in the older children (i.e., more succinct and economical answers to questions, which also explains the rise in partial or fragmentary sentences). Finally, we found significant decreases with age from 5 to 8 in overall error rates, a finding that was due primarily to a developmental drop in morphological errors, especially overregularizations like "goed" or "comed". There were also significant interactions between age and lesion group on total errors, due again to morphological errors. Inspection of cell means indicated that this interaction is coming primarily from the youngest children with brain injury (both LHD and RHD), who appear to be lagging a bit behind their normal age-mates. There were, however, no differences between children with RHD and children with LHD at any age, a harbinger of results that we report in more detail below.

To understand why age effects in the 5- to 8-year range are so small, it is important to keep in mind that the fundamental phonological, lexical and grammatical elements of language are generally acquired (in the sense that they can be used productively in at least some linguistic contexts) by 4-5 years of age in most normal children. Although further development is certainly observed after this point in fluency, vocabulary size, and the accessibility and use of grammatical knowledge in highly structured contexts, we should not be surprised to find that relatively little development shows up between 5 and 8 in open-ended contexts like the biographical interview, where children have considerable control over the structures they choose to employ (and the questions they choose to answer).

Because our developmental findings between 5 and 8 years are relatively few and quite small, in the interests of economy all remaining analyses were conducted collapsing across the 5- to 8-year age range for child participants. Hence all developmental results reported below will refer to overall differences between child and adult participants.

\section{Analysis of Speech Output: Amount and Length}

Our primary measures of amount of speech are of course highly interdependent, including raw scores for number of utterances (roughly analogous to speaking turns-MacWhinney \& Snow, 1995), number of word tokens, number of word types, and number of morphemes. However, these measures are sensitive to different aspects of speech output, and hence might offer different insights into the effects of unilateral lesions on language production by children vs adults. To deter- 
mine whether there were any interesting differences in the distribution of these speech output variables over age and lesion groups, we began with a multivariate analysis of variance treating Age (child vs adult) and Lesion Group (Normal, LHD, and RHD) as betweensubjects factors and the output variables as a single four-level within-subjects factor. The relevant results for this analysis included significant two-way interactions of Age $\times$ Output Variable $[F(3,309)=37.82, p$ $<.0001]$ and Lesion Group $\times$ Output Variable $[F(3$, $309)=7.32, p<.0001]$, as well as a three-way interaction of Age $\times$ Lesion Group by Output Variable [F(3, $309)=6.74, p<.0001]$. These three effects mean that our four measures of amount of speech do indeed pattern differently as a function of both age and lesion category. More important for our purposes here, the nature of the Lesion Group $\times$ Output Variable interaction differed for children vs adults.

To explore results for each of these variables considered separately, we will follow the plan of analysis described above (see Table 4 for details).

Number of utterances. An Age $\times$ Lesion Group analysis on this variable yielded no main effect of lesion group, but there was a significant main effect of age (reflecting a global tendency for adults to produce more utterances), together with an age by lesion interaction. The interaction is illustrated in Figure 1, which also includes a further breakdown of the LHD patients by aphasia category (Broca's, Wernicke's, anomics and nonaphasic LHD).

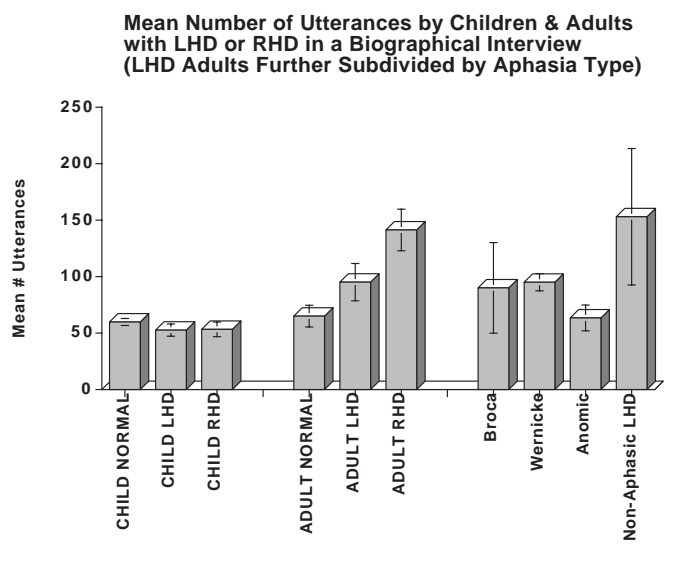

Figure 1

Several findings are evident in Figure 1 (and all are significant at $\mathrm{p}<.05$-see Tables 3 and 4 for numerical details).

First, children between 5 and 8 years of age talk much less than adults (including brain-damaged adults), a finding that will show up again as we examine other speech output measures.

Second, the sheer number of utterances produced is not necessarily a good index of preserved language abilities. In fact, our normal adult controls took substantially fewer speaking turns than any patient group except for the mildly impaired anomics. In the case of the more severely impaired aphasics (Broca's and Wernicke's), this relative overproduction of utterances reflects their linguistic disorganization: Normals can make a succinct point in a single well-formed response to the interviewer's question, while these patients often have to make several attempts to get the same point across.

Third, the means for the seven patients with RHD and for the three nonaphasic patients with LHD indicate that many of these individuals simply cannot stop talking, producing more than twice the average number of speaking turns observed in normal adults. This garrulous behavior in a biographical interview may reflect some form of disinhibition, a symptom that can manifest itself in open-ended situations like the biographical interview but may not be evident in their performance on more structured tests. The resemblance between nonaphasic patients with LHD and nonaphasic patients with RHD is interesting in its own right, raising the oftcited hypothesis that some adults who recover apparently unscathed from a left-hemisphere stroke may have been cross-dominant or bilaterally organized for language prior to their injury.

The fourth result suggested by Figure 1 is the most important one for our purposes here: no apparent effect of lesion group in our child participants compared with large and varied effects of lesions in adults. To quantify this impression, we conducted a series of post hoc tests, in a plan of analysis that we will follow for our other measures below. First, we carried out a simple one-way analysis of variance over lesion group within the respective child and adult samples. There was absolutely no significant effect of lesion group for children, but the corresponding effect was significant for adults. We also carried out pairwise comparisons among LHD, RHD, and normals within each age level. As we would expect from the one-way anova, none of these comparisons reached significance among the children. For adults, the corresponding $t$ tests indicated that patients with RHD produce more utterances than normals, but the other two comparisons (RHD vs LHD, LHD vs normals) did not reach significance. Hence the main result for this particular measure is an overproduction of utterances by adult patients with RHD compared with normal controls (but see nonaphasic LHD, as noted above).

Finally, we compared results for children and adults directly within each lesion category. Using raw scores, post hoc $t$-tests showed no difference between normal children and normal adults in number of utterances produced. However, within the respective patient categories, LHD adults produced more utterances than LHD children, and RHD adults produced more utterances than RHD children. These results for child vs adult patients also hold up if we substitute $z$ scores (based on performance by age-matched controls): LHD adults produce relatively more utterances than LHD 
children, and RHD adults produce relatively more utterances than RHD children. As summarized in Table 3 , the use of $z$ scores also permits us to look more closely at differences across the adult aphasia subtypes: all the patient groups except our mildly impaired anomics have $z$ scores between +.75 and +2.64 , indicating a substantially higher than normal number of utterances in brain-injured adults.

Number of word tokens. This measure gives us a slightly different perspective from number of utterances (above), because it is more sensitive to the absolute amount of speech and less sensitive to its division into speaking turns. The Age $\times$ Lesion analysis of variance on this measure yielded a significant main effect of age, reflecting more word production overall by adults, as well as a significant main effect of lesion group and an age by lesion group interaction. The interaction is illustrated in Figure 2, which also includes a breakdown across aphasia subgroups within the LHD sample. Figure 2 suggests several conclusions that are largely compatible with the previous analysis, with some interesting additions: (1) adults generally produce more words than children in this situation; (2) there are no effects of lesion group on the number of words produced by children; (3) by contrast, there are complex effects of lesion group (and aphasia category) on word production by adults, including (a) further evidence for disinhibition in RHD patients and nonaphasic patients with LHD, who produce more words than normal, and (b) underproduction of words by nonfluent Broca's aphasics and by the anomic group, while (c) the more fluent Wernicke's aphasics appear quite normal on number of words produced (an impression that disappears later when we look at more qualitative measures of language production).

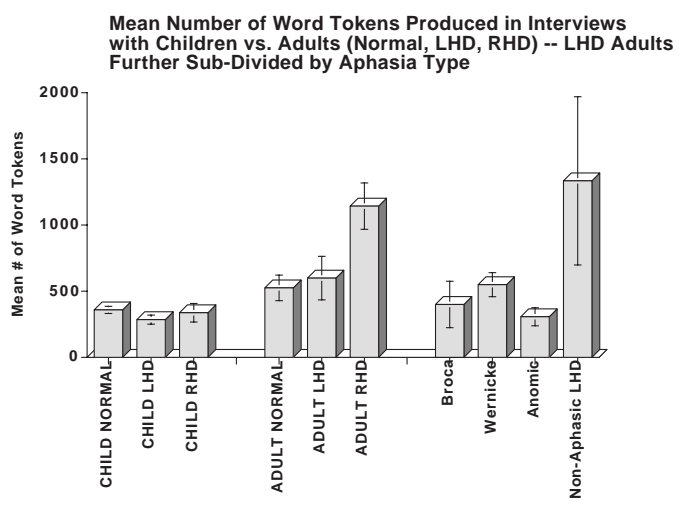

Figure 2

Finally, we compared children and adults directly within each lesion group, on raw scores and (for the respective LHD and RHD patients) on $z$ scores based on performance by age-appropriate normal controls. In all three comparisons using raw scores, adults produced more word tokens than children. However, when agebased $z$ scores were used, the adult advantage disap- peared for LHD, but remained significant for RHD. Thus we can begin to see the additional perspective that can be derived from the use of $z$ scores correcting for age. The $z$ scores summarized in Table 3 also clarify the range of outcomes that can be observed in braininjured adults, with Broca's and anomics both producing fewer words than normals ( $z$ scores of -.37 and -.65 respectively), Wernicke's producing word output very close to normal $(\mathrm{z}=+.07)$, while RHD patients $(\mathrm{z}$ $=+1.85)$ and nonaphasic patients with LHD $(\mathrm{z}=+2.42)$ are far ahead of normals in the number of words they use within this biographical interview.

Number of word types. A type/token ratio is sometimes used to quantify the notion of lexical diversity. However, these ratios can be quite misleading when they are applied to aphasic patients (or to very young children—see Bates, Bretherton, \& Snyder, 1988). For example, a severely agrammatic adult aphasic or a normal 24-month-old child might produce relatively high type/token ratios not because they are high in lexical diversity, but because they produce telegraphic speech, omitting function words (which are frequently repeated in normal speech, lowering type/token ratios). Hence for present purposes we evaluated lexical diversity by examining word types and word tokens separately.

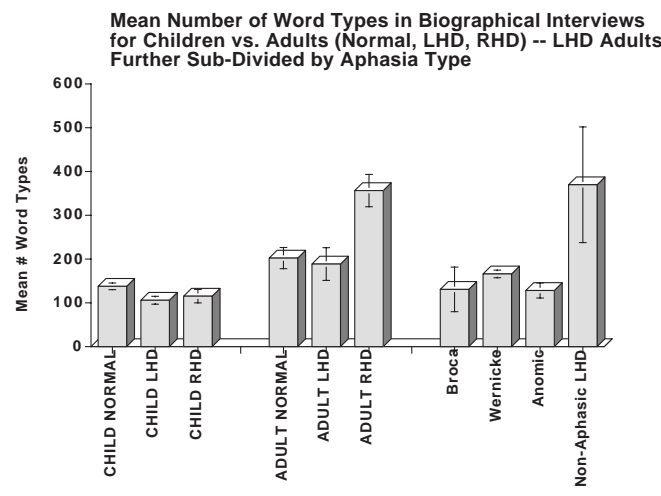

Figure 3

An Age $\times$ Lesion analysis of variance on number of word types resulted in a significant main effect of age (reflecting greater lexical variety in adults overall), a significant main effect of lesion, and an age by lesion interaction. The interaction is illustrated in Figure 3, with a further breakdown of the adult LHD group into aphasia subtypes. This figure illustrates some of the same patterns provided by the first two measures, but it also introduces some new information. In keeping with our findings for total utterances and total word tokens (i.e., "old news"), we can see once again that adults talk more than children overall, that RHD patients and nonaphasic patients with LHD talk more than normals, and that the various aphasia subtypes differ markedly in the number of word types produced. The new information in Figure 3 includes two further trends. First, despite the fact that they produce a 
normal number of utterances with a normal number of words, Wernicke's aphasics score below normal controls on lexical variety. In other words, fluent Wernicke's aphasics tend to repeat themselves, producing a high proportion of "empty speech." This finding is not new, but it provides some validation of the measures we have chosen. Second, the two child patient groups together seem to have a slight disadvantage in lexical diversity compared with their age-matched controls.

As Table 4 shows, number of word types is one of the only variables that yields any hint of a subgroup difference for children in post hoc analyses. There is no significant difference between LHD and RHD children on this measure. However, children with LHD produced significantly fewer word types than normals $(p<.01)$; a trend in the same direction was observed for RHD vs normals but it missed significance $(p<.16)$. We bring this detail to the reader's attention because it illustrates a serious methodological problem in the literature on language outcomes in brain-injured children. As we noted in the introduction, some of the earlier studies of language outcomes in this population compared LHD and RHD children with separate control groups in multiple analyses, but LHD and RHD were never compared directly. On a handful of measures in those studies, the difference between LHD and controls reached significance but the difference between RHD and controls did not. Such findings were used to argue for differential outcomes following left- vs right-hemisphere damage, even when the injuries occur early in life (see Bishop, 1983, for a critical review). If we were to follow that analytic strategy in our analysis of word types, we would conclude based on above findings that children with LHD have a selective deficit in lexical diversity that is not present in children with RHD. And yet, as we have also seen, there is absolutely no difference between LHD and RHD when they are compared directly on this measure. Hence it would be inappropriate to conclude that the two lesion groups display qualitatively or quantitatively different patterns. We will return to this point later.

Finally, we once again conducted direct comparisons of children vs adults within each lesion group. Using raw scores, we find that adults produce more word types than children within all lesion categories. However, when $z$ scores are used instead of raw scores, the adult-child difference disappears for LHD patients but remains strong for RHD patients. Another way of thinking about this is that left-hemisphere damage can wipe out the relative advantage in lexical diversity that we usually see in adults, while RHD leaves the adultchild difference intact (or may even amplify it, reflecting the garrulous and disinhibited pattern displayed by some of these adult patients). This exercise underscores the value of using age-based $z$ scores to compare children and adults.

Number of morphemes. Because English is a language with a rather spare system of grammatical morphology, number of morphemes and number of words overlap markedly as measures of speech output (see Bates, Wulfeck, \& MacWhinney, 1991 for a discussion of this issue). Hence it is not surprising that there were no interesting differences between our analyses of word tokens and number of morphemes in the various analyses that we have described so far (see Tables 3 and 4). In fact, when we repeated all of the analyses reported above on total number of morphemes (including the overall analysis of variance by Age and Lesion Group, and all of the same post hoc analyses), results for the two measures differed in only one respect: the difference between adults with LHD and RHD reached significance for total number of morphemes $(p<.035)$, reflecting fewer morphemes in speech by LHD patients, while the corresponding analysis missed significance for total number of word tokens ( $p$ $<.054)$. In the interests of economy, we will refer the reader to Tables 3 and 4 for details within and across subgroups on total number of morphemes, and proceed directly to an analysis of utterance length in which the total number of morphemes produced by each patient is calculated as a ratio of total utterances (i.e., mean length of utterance in morphemes, or MLU).

Mean Length of Utterance in morphemes (MLU). MLU is a widely used measure in research on child language development; it is used less often in research on adult aphasia, but it provides a useful basis for comparison of children and adults. Of the measures that we have reported so far, this is also the first one that controls for overall amount of speech.

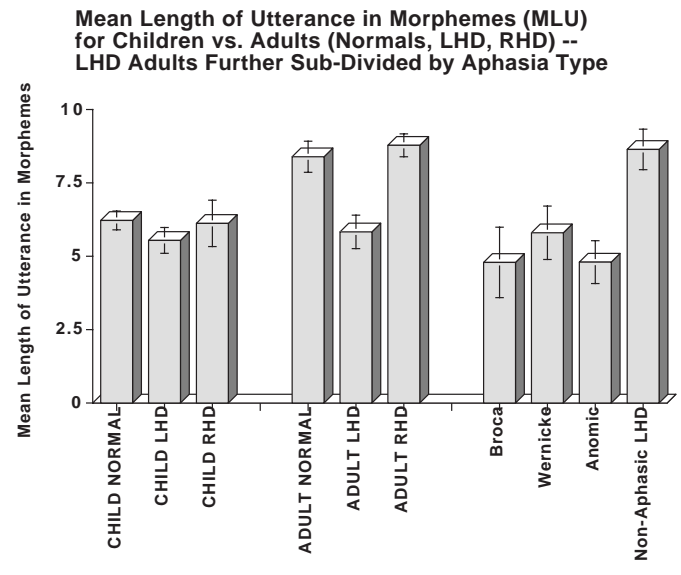

Figure 4a

Figure 4a illustrates the range of variation observed on MLU in morphemes for children vs adults, broken down by lesion group (with the LHD adults also broken down by aphasia subtype). An Age $\times$ Lesion Group analysis of variance yielded significant main effects of age (reflecting a tendency for children to produce shorter utterances) and lesion group, but the age by lesion interaction missed significance $(p<.08)$. Although the interaction was not significant, we ad- 
hered to the plan of analysis adopted throughout the article and conducted separate one-way analyses of variance over Lesion Group for children vs adults. In the analysis for children, there was no main effect of lesion group, and paired comparisons also confirmed that there were no significant differences between any of the child subgroups on MLU (see Table 3).

In contrast with the even MLU profiles displayed by children, the main effect of Lesion Group on MLU did reach significance for adults. Figure 4 a shows that there is striking variation across the various adult subgroups on this measure, although the talkativeness observed earlier in RHD and nonaphasic LHD is much less evident on MLU, which takes the total number of utterances into account. In fact, paired comparisons revealed no significant difference in MLU between RHD ( mean $=8.78)$ and normals $($ mean $=8.39)$. By contrast, LHD patients (mean $=5.83$ ) scored significantly below both normals and RHD. A close examination of the cell means in Table 3 (see also Fig. 4a) shows that all of the aphasic subgroups share a marked disadvantage in MLU, with mean subgroup scores between 4.79 (for Broca's aphasics) and 5.80 (for Wernicke's aphasics). Only the nonaphasic LHD patients score within the normal range (8.64). Hence, in contrast with our other measures of total speech output, MLU distinguishes between aphasic and nonaphasic patients, while reducing the effects of the garrulous and disinhibited pattern of speech in RHD and nonaphasic LHD uncovered by our other measures of speech output (compare Figs. 1-3 with Figs. 4a and 4b).

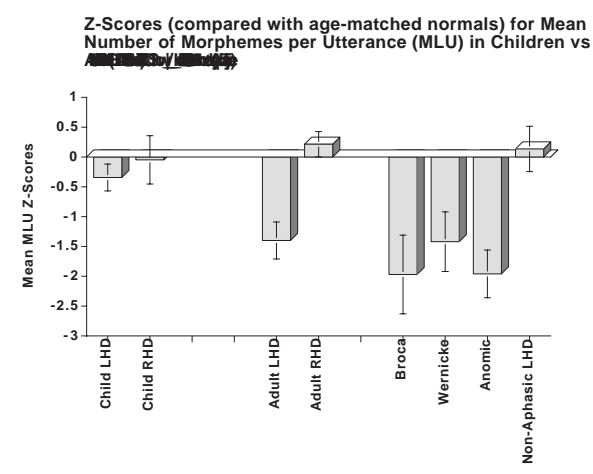

Figure $4 \mathrm{~b}$

When children and adults were compared directly on raw MLU, a significant adult advantage emerged for normals and RHD, but not for LHD. In other words, left-hemisphere damage in adults results in utterances that are similar in length to the utterances produced by normal 5 to -8-year-old children. However, when MLU is calculated in age-appropriate $z$ scores, things look rather different: It is now clear that children with LHD have a significant relative advantage over adults with LHD, while children and adults with RHD did not differ significantly from one another. Figure $4 \mathrm{~b}$ illustrates the profiles that are obtained when $z$ scores are used instead of raw scores to measure mean length of utterance. A comparison between Figures $4 a$ and $4 b$ clarifies why it is useful to take expected level of development into account in comparing the effects of unilateral injury on children vs adults.

To summarize our results for both amount and length of speech, we have found on every measure that children talk less than adults in this situation, but there are no significant differences between children with LHD vs RHD. Furthermore, child patients fell significantly below their normal controls only on the number of word types that they produce. By contrast, we found striking differences among the adult subgroups on every measure, including LHD/RHD differences that are not observed in the child sample. Some of these differences reflect scores below normal for adult patients with LHD (e.g., on MLU). However, other results reflect scores that are significantly higher than normal in brain-injured adults. This includes a tendency for RHD patients and nonaphasic patients with LHD to produce up to twice as much speech as normal adults, reflecting what may constitute a form of disinhibition. It also includes a tendency for severely aphasic patients to produce more utterances than normal in this biographical interview, reflecting a degree of disorganization (e.g., many attempts required to make a point) that is not observed in the succinct but informative responses provided by normal controls.

Because there are such marked disparities across subgroups in total output and mean utterance length, all of the more qualitative analyses that follow were calculated on the first 100 utterances (or fewer) for each participant. Although this decision did reduce the effects of talkativeness in RHD and nonaphasic LHD patients, there were still marked differences between children and adults (and the various adult subgroups) in the total number of utterances available for analysis. Hence all complexity and error scores were calculated as proportions of total output. Measures of propositional complexity (total number of propositions) and syntactic complexity (both types and tokens) were divided by the total number of utterances produced (similarly to the above calculation of MLU). Our measure of fragmented (elliptical) vs complete sentences was calculated as a proportion of all sentence tokens (regardless of their division into utterances or speaking turns). The various error types (morphological errors, lexical errors and omissions) were calculated as a proportion of the total number of propositions attempted by each child or adult speaker. We used propositions rather than utterances as the denominator for error scores because previous studies in our laboratory had shown that controlling for propositions yields a more sensitive index of morphological complexity (Reilly et al., 1998).

\section{Measures of Complexity}

Table 3 provides cell means for all child and adult subgroups (including a breakdown of LHD adults by 
aphasia subtype) on each measure of complexity, both raw scores and $z$ scores, including propositions per utterance, complex syntactic tokens per utterance, complex syntactic types per utterance, and number of sentence fragments as a proportion of all sentences produced. Table 5 provides details of statistical analyses for these measures. Although these measures are correlated, they are so different in structure and direction that we did not attempt a multivariate analysis of variance with complexity type as a variable, but moved directly to Age $\times$ Lesion group comparisons and corresponding post hoc analyses on each individual measure. The one exception (reported in the text below) is a multivariate analysis of variance comparing complex syntactic types and tokens.

Propositions per utterance. As noted under Methods, propositions were defined around main verbs and their arguments, which means that this measure reflects a combination of semantic and syntactic complexity. Because the individual verbs used to define a proposition have to be expressed overtly, this also means that propositional complexity is sensitive to any problems that a patient might experience in lexicalization of verbs. For example, several studies have reported that nonfluent Broca's aphasics have deficits in verb production, evident in free speech and in tasks that require naming of actions vs objects outside of a sentence context (for a review, see Chen \& Bates, 1998). Such a deficit would necessarily result in low levels of propositional complexity as it is defined here.

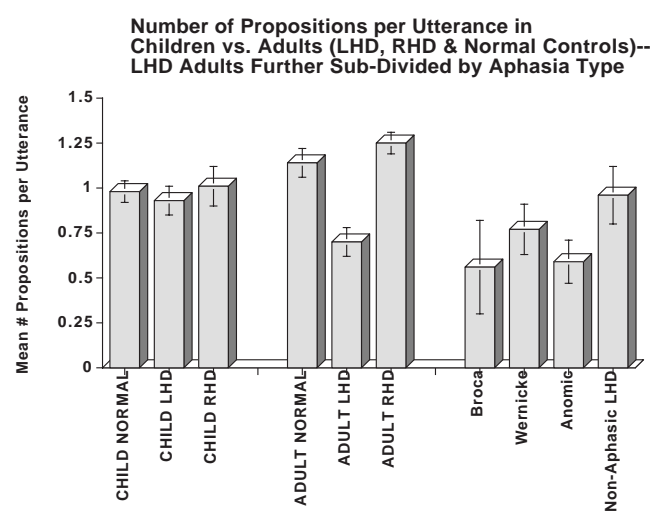

Figure 5a

An Age $\times$ Lesion Group analysis on proposition/ utterance ratios yielded no significant main effect of age, but it did reveal a main effect of lesion and an age by lesion interaction. The interaction is illustrated in Figure 5a, which also includes a breakdown of LHD adults by aphasia subtype. The interaction is explained by separate analyses for children and adults, which yield what is starting to sound like a very familiar pattern: no effect of lesion group for children, and significant effects of lesion group for adults. Post hoc comparisons showed that adult LHD patients produced proportionally fewer propositions than both RHD patients and normals, but RHD and normals did not differ. Figure 5a also shows that all aphasic subgroups are at a marked disadvantage in propositional complexity, compared with normals, RHD and nonaphasic LHD patients. This last point is even more evident when proposition/utterance ratios are expressed as $z$ scores, illustrated for comparison in Figure $5 \mathrm{~b}$. Note that all the aphasic subgroups are between 1 and 2 standard deviations below the normal adult mean in propositional complexity. This is also one area in which we see a difference between RHD (who are +.37 standard deviations above the normal mean) and nonaphasic LHD (who are - 63 standard deviations below the normal mean).

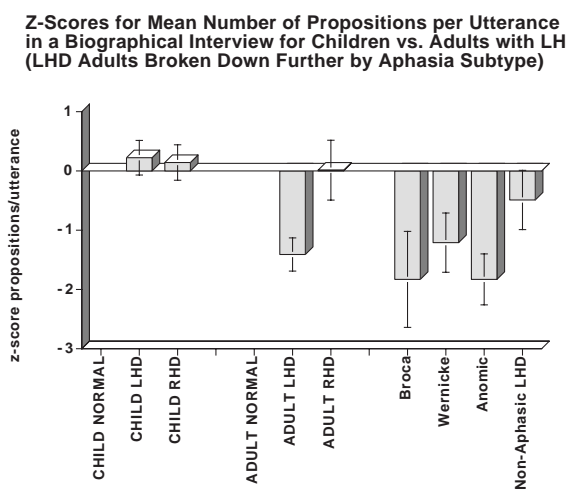

Figure 5b

Finally, adults and children were again compared directly within each lesion group, using both raw proportion scores and age-appropriate $z$ scores. When raw proportion scores were used, there was no significant adult/child difference among normals or patients with RHD; the adult/child comparison also failed to reach significance for LHD, although there was a trend $(p<.062)$ reflecting greater propositional complexity in LHD children compared with LHD adults. This picture comes into sharper focus when propositional complexity is examined using age-appropriate $z$ scores (see Fig. $5 b$ ). In this set of comparisons, we now see a significant disadvantage for LHD adults (reflecting a mean $z$ score of -1.52) compared with LHD children (who have a mean $z$ score of -.14). In other words, by taking developmental level into account, we are able to show that LHD is associated in adults with a significant loss of propositional complexity that is not seen in children. In children vs adults with RHD, the same comparisons were not significant; both RHD groups are operating within normal levels of propositional com-plexity for their age (i.e., mean child $z$ score $=+.09$; mean adult $z$ score $=+.37)$.

Syntactic complexity: Tokens \& types. Appendix C summarizes the range of syntactic structures that were categorized as complex types. Scores were calculated in number of types as well as number of tokens and divided by total number of utterances in both cases. 
These type and token scores for complex syntax are closely related, but they are also sensitive to different aspects of speech planning. Token scores do not take repetitions into account, and hence they may be inflated by the repeated use of formulaic utterances like "I think $\mathrm{X}$ " or even by circumlocutions like "I don't know how to say X". Hence type scores may provide a more valid index of syntactic diversity.

To determine whether these two complexity measures pattern differently across age levels and lesion groups, we began with a multivariate Age $\times$ Lesion Group analysis of variance treated Complex Types and Tokens as two levels of a single within-subjects variable. The relevant results of this multivariate analysis include a significant two-way interaction of Lesion Group $\times$ Type/Token $[F(2,206)=6.56, p<$ .002] and a significant 3-way interaction of Age $\times$ Lesion Group $\times$ Type/Token $[F(2,206)=3.98$, $\mathrm{p}<$ .022]. These interactions support our contention that type and token scores reflect partially separable aspects of speech planning, which are in turn associated with differential effects of age and lesion type.

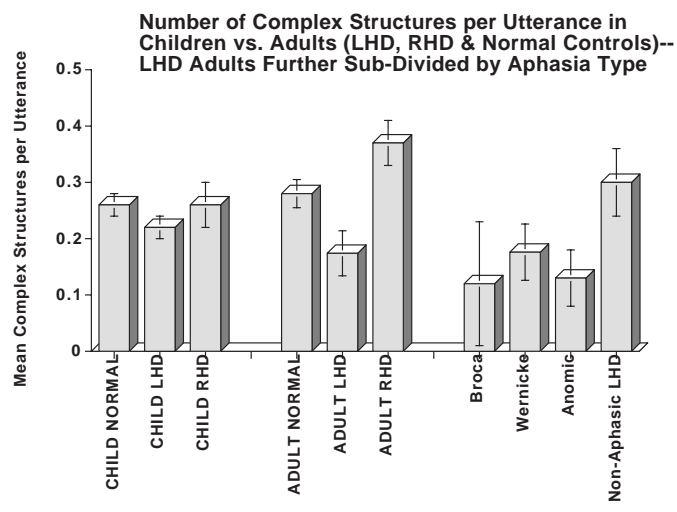

Figure 6a

Figures $6 \mathrm{a}$ and $6 \mathrm{~b}$ plot the age by lesion group effects for these two variables expressed as raw proportion scores. Figure $6 \mathrm{c}$ presents the same information for both measures in $z$ scores. Examination of these figures suggests a possible locus for the three-way interaction, namely, a complete reversal for adults with RHD on complex tokens vs complex types. In fact, RHD adults score more than a standard deviation above the normal mean on complex syntactic tokens $(z=$ $+1.05)$, but they score more than a standard deviation below the normal mean on complex syntactic types $(z=$ $-1.03)$. Hence their apparent syntactic sophistication is an illusion, reflecting overuse of a small set of structures. By contrast, adults with LHD score poorly across the board, on complex syntactic tokens $(z=-1.25)$ as well as types $(z=-1.78)$. When the LHD adults are broken down by subtype, all three aphasic subgroups (Broca's, Wernicke's, anomics) average at least one standard deviation below normal on both complex types and complex tokens. However, nonaphasic adults with LHD display a weaker variant of the pattern observed with RHD: above the mean on complex tokens ( $z$ score mean $=+.24)$ and below the mean on complex types $(z$ score mean $=-.81$ ).

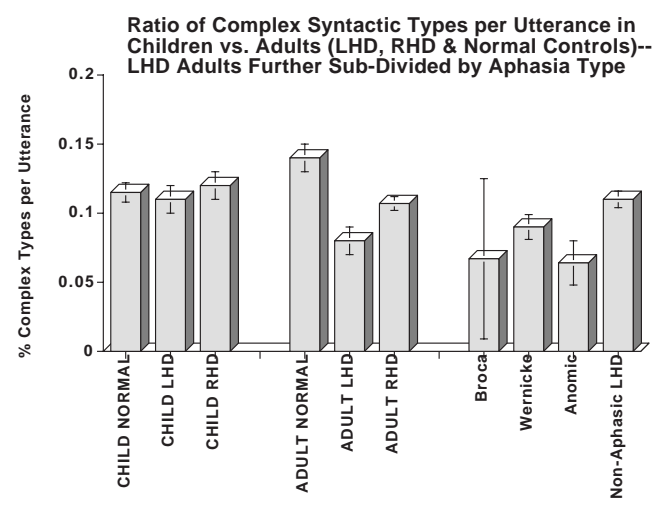

Figure 6b

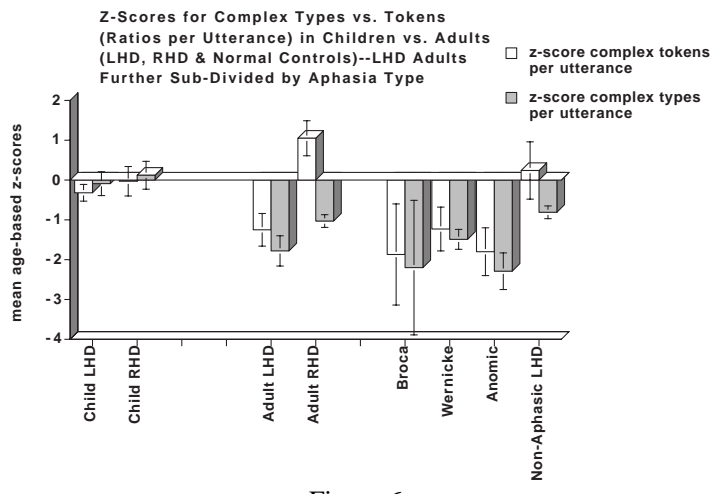

Figure 6c

The corresponding Age $\times$ Lesion Group analysis of complex types per utterance yielded a different pattern. In that analysis, there were no main effects of age or lesion group, but the interaction was significant. Separate one-way analyses of lesion group once again showed no significant effect for children. The corresponding analysis for adults did produce a significant effect of lesion; in post hoc comparisons, the difference between LHD and RHD missed significance, but LHD and RHD both scored significantly below normals. In other words, RHD switch from "overproduction" when complex syntax is measured in tokens (as described in the previous section) to "underproduction" when complex syntax is measured in types, while LHD are depressed on both measures. Table 3 indicates that a similar reversal is also observed in our small group of nonaphasic patients with LHD, who score above the normal mean in production of complex tokens $(z=+.30)$ but well below the mean on production of complex types $(z=-.81)$.

Finally, we again carried out direct child/adult comparisons within each lesion group. When raw proportion scores were used, none of the child-adult 
comparisons reached significance for complex tokens, although there was a trend toward more complexity in RHD adults compared with RHD children. On complex types, there was a trend toward an adult advantage among normal children and adults, but no such advantage appeared for adults with LHD or RHD. The picture clarifies again when adult and child patients are compared using age-appropriate $z$ scores. LHD adults received $z$ scores significantly below LHD children on both complex tokens and complex types. In other words, left-hemisphere damage results in a (relative) deficit in syntactic complexity for adults that is not seen in children, no matter how complexity is measured. For RHD patients, there was a trend toward an adult advantage on complex tokens, but there was a significant adult disadvantage on complex types.

To summarize results for production of syntactically complex forms, adults show a huge array of variation as a function of lesion side and aphasia subgroup, while children show no significant effects of any kind (i.e., no difference between LHD and RHD, and no evidence that early injuries lead to a significant disadvantage on these measures). Among the adults, the contrast between complex tokens and complex types produced an interesting reversal for patients with RHD (and, to a lesser extent, nonaphasic patients with LHD): in contrast with our LHD aphasics (who averaged more than a standard deviation below normal on both tokens and types), the nonaphasic patients produce more complex tokens but fewer complex types than normal controls. This finding is compatible with the garrulous and disinhibited conversational profile that emerged in the analyses described above, suggesting that the apparent syntactic sophistication of our nonaphasic patients may reflect a tendency toward repetition and overreliance on formulaic constructions.

Percentage of sentence fragments of all sentences produced. We define "fragments" as sentences with missing constituents that would be obligatory if the sentence were produced in isolation, but are perfectly grammatical when they are produced in a conversational situation. Hence this measure does not include ungrammatical omissions (which are treated separately later on). In a biographical interview situation, this measure tells us something about the active vs passive nature of a given speaker's participation, i.e., responding to the interviewer's questions without elaboration (resulting in a high proportion of ellipsis) or taking the initiative and expanding on these questions, taking the conversation in new directions (in ways that may or may not be appropriate to the social situation).

All effects were significant in the Age $\times$ Lesion analysis of variance, including a main effect of age, reflecting more fragmented or elliptical speech overall in children, a main effect of lesion group, and an age by lesion group interaction. The interaction for raw proportion scores is illustrated in Figure 7a; Figure $7 \mathrm{~b}$ plots age-based $z$ scores for child vs adult patients on the same measure.

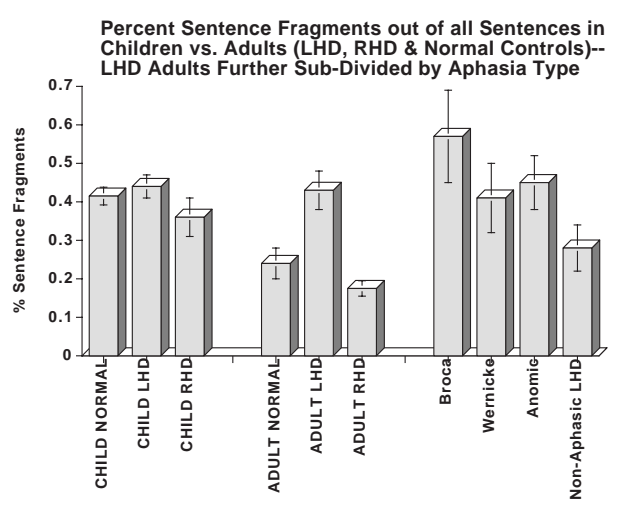

Figure 7a

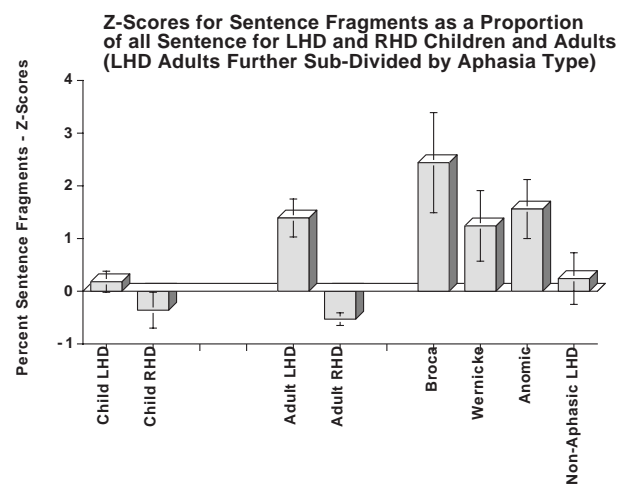

Figure $7 \mathrm{~b}$

When adults and children were analyzed separately, the main effect of lesion type was once again nonsignificant for children but significant for adults. Among adults, LHD had higher fragmentation scores than both RHD and normals, while there was no difference between RHD and normals. Hence the sentence fragment scores are sensitive to language problems among brain-injured adults, but reveal no differences of any kind of children. Among the LHD patients (see Table 3 for details), all aphasic subgroups produced abnormally high sentence fragment scores. However, this tendency was substantially greater for Broca's aphasics (with a raw proportion scores averaging $57 \%$ and $z$ scores averaging +2.44 ), reflecting the elliptical speech that is a hallmark symptom in Broca's aphasia (Kolk \& Heeschen, 1990, 1992).

We again compared children and adults directly within lesion groups. On raw proportion scores, normal children scored significantly above normal adults, reflecting the more passive discourse stance that children tend to take in this interview situation. The same pattern also reached significance between adults and children with RHD, but not between adults and children with LHD. Another way of saying this is that lefthemisphere damage reduces adults to patterns of ellipsis similar to those of children between 5-8 years of 
age. However, when $z$ scores were used instead of raw proportion scores, a significant difference favoring children emerged in the analysis for LHD, reflecting a mean fragmentation $z$ score of +1.39 for LHD adults as a group, compard with a $z$ score of +.18 for LHD children (i.e., well within the normal range for their age). There was no comparable difference between adult and child $z$ scores within the RHD group, which means that RHD children and RHD adults are both normal for their age on this measure.

\section{Error Analyses}

Errors were classified into four mutually exclusive categories: frank omissions (each referring to a single instance in which it was clear that one or more content and/or function words were missing - the number of missing words in a given instance did not affect the score), morphological errors (omission or substitution of an obligatory bound morpheme, or incorrect selection of a preposition or pronoun), lexical errors (production of the wrong content word or a nonword), and a remaining category "other" to capture errors that proved impossible to classify (the "other" category proved to be extremely rare for any group except Broca's aphasics). To control for individual or group differences in overall amount of speech, all error scores were expressed as a proportion of the number of propositions produced (see Methods). Details for all error types, for each subgroup, are contained in Table 3.

Table 6 summarizes details from statistical analyses.

Total errors per proposition. Figure 8a plots total errors per proposition for each lesion group (with adult LHD further broken down by aphasia subtype). In that figure, error columns are also subdivided to illustrate the proportions contributed by omission, morphological, lexical errors, and "other", respectively. Further details (cell means and standard errors for each group, for each measure) are provided in Table 3. Figure $8 \mathrm{~b}$ presents total errors per proposition in age-appropriate $z$ scores, for child vs adult patients.

We begin with an overall Age $\times$ Lesion Group analysis of variance on total error scores per proposi-, which yielded no main effect of age, but did yield a significant main effect of lesion group and a significant age by lesion group interaction. Separate one-way analyses by Lesion Group showed once again that the effect of lesion is significant for adults but not for children (although there were trends toward more errors than normal in both child lesion groups, $p<.11$ for LHD; $p<.08$ for RHD, reflected in $z$ score error rates that are somewhat higher than normal, $\mathrm{z}=+.56$ for LHD and $z=+.76$ for RHD).

Paired comparisons for adults showed that normals produce significantly fewer errors than both LHD and RHD. Although there was a trend toward more errors in the left-hemisphere patients, the difference between LHD and RHD missed significance $(p<.13)$. In other words, error rates are higher than normal in all brain-

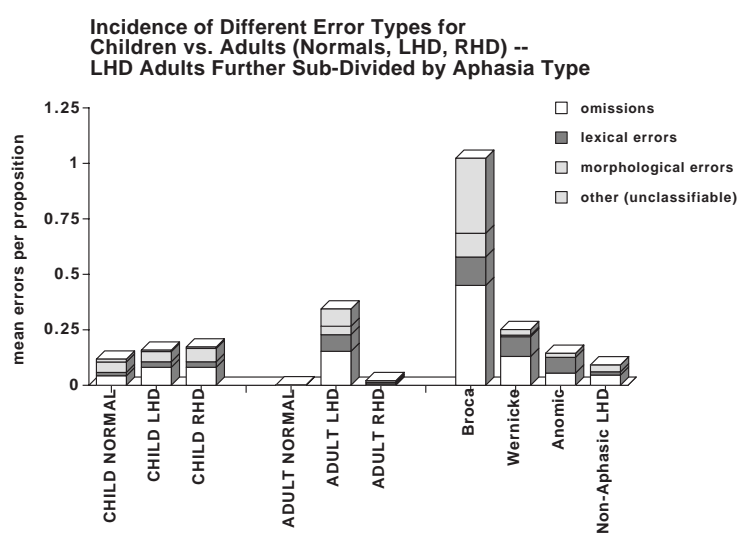

Figure 8a

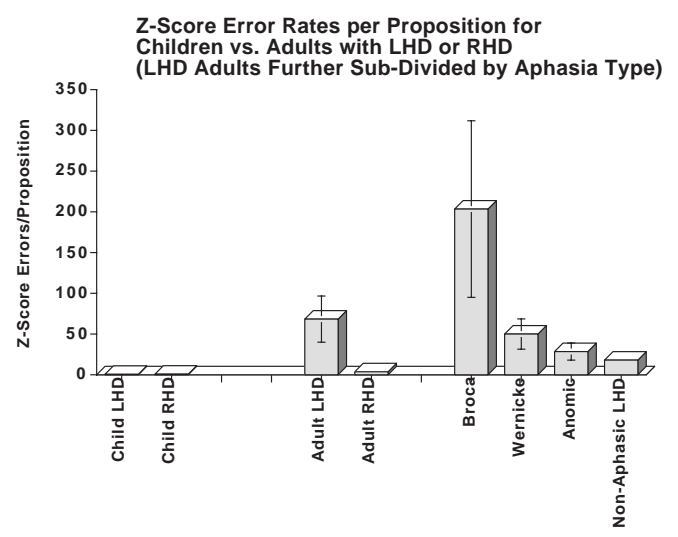

Figure $8 b$

injured adults, even among patients who do not meet clinical definitions of aphasia. Furthermore, because the error rates for normal adults are exceedingly small (with very small standard deviations), the $z$ score error rates for adult aphasic patients are correspondingly high across the board, ranging from a low of +28.48 in anomics to an astonishing high of +203.4 in Broca's aphasics. These extreme scores place in perspective the high (but less astonishing) $z$ score of +18.00 in nonaphasic adults with LHD and +3.71 with adults with RHD.

From direct comparisons on raw proportion scores, we begin to see just how different the linguistic situation is for children vs adults, including normals. Among normals, paired comparisons reveal a robust advantage for adults, whose mean overall error rate is only .002 (i.e., two errors out of every 1000 propositions), compared with a mean overall error rate of .12 for children (i.e., $12 \%$ of all propositions). Among patients with LHD, the adult/child comparison just misses significance $(p<.11)$, but in this case the advantage goes to children (16\% errors in children with LHD compared with $34 \%$ in adults with LHD). Among patients with RHD, we go back to the same significant 
adult advantage that was observed with normals, reflecting an average of $2 \%$ errors out of all propositions in RHD adults vs $17.4 \%$ in RHD children. When these are converted to $z$ scores, paired comparisons reveal a significant disadvantage for LHD adults com-pared with LHD children, but no difference whatsoever for RHD adults vs RHD children. Once again, we can see that left-hemisphere damage has a serious effect on linguistic performance in adults but little or no effect on children. All of this must be understood, however, against a developmental background in which all children (including normals) continue to produce errors that have all but disappeared in healthy adults. The nature of this developmental lag will be clarified as we examine age by lesion effects within specific error types.

Omission errors. Because adult controls did not produce a single example of an omission error, there is no variance for omission errors in that cell, precluding parametric analyses involving this group. A separate three-way Lesion Group analysis for children yielded a significant main effect of lesion group, one of the few that we have obtained in this study. However, paired comparisons showed that this lesion effect in children is due to a generic effect of brain damage: Omission rates averaged $8.1 \%$ in children with LHD and $8.1 \%$ in children with RHD, a very clear "nondifference", but these omission rates were significantly higher than the mean of $4.3 \%$ observed in normal children. Among adults, the two-way Lesion Group comparison between LHD $($ mean $=15.3 \%)$ and RHD $($ mean $=0.6 \%)$ also failed to reach significance, although there was a trend in the expected direction ( $p<.09$ by a two-tailed test). A detailed breakdown of patients by aphasia subtype (Table 3 and Fig. 8a) shows that the variation in omission rates among LHD patients is very large, ranging from $4.6 \%$ in nonaphasic LHD to a startling $45 \%$ in Broca's aphasics (i.e., almost half of all propositions attempted by these patients contained an omission error). Of course this is not surprising, since omission is the hallmark error of nonfluent Broca's aphasics, but a deficit this severe in aphasic adults helps to put the developmental findings into perspective.

We were also unable to calculate $z$ score values for omission among our adult groups, because adult normals did not produce a single instance of an omission error. This means, of course, that the standard deviation for normal adults is 0 , which cannot be used as a divisor to calculate $z$ scores. In the absence of adult $z$ scores, direct adult/child comparisons were conducted on raw omission rates only, revealing a significant adult advantage among normals, a significant child advantage among patients with LHD, and a nonsignificant trend ( $p$ $<.09)$ toward an adult advantage among patients with RHD.

Morphological errors. Like omission errors, morphological errors occur fairly frequently even in perfectly healthy children between 5 and 8 years of age. However, such errors are exceedingly rare in normal adults in the informal discourse context used in the present study. Particularly interesting in this regard is the specific subcategory of overgeneralization errors (e.g., "goed" instead of "went"), one of the two measures used here that underwent a significant drop between 5 and 8 years. Most of our 5- to 8-year-old children produced at least one or two of these errors, on average, and they were especially common in the 5year-olds (who averaged about 6 overgeneralizations each across the whole interview). However, overgeneralization errors were nonexistent in our adult sample, including severe Broca's and Wernicke's aphasics who experience serious problems with grammar. This result contrasts markedly with recent claims in the literature on regular vs irregular morphology (Pinker, 1991; Ullman et al., 1997). Proponents of the "dual mechanism" view have argued that regular morphemes (including the past-tense marker "-ed") are mediated by a rule-based system based in frontal and basal gangliar circuitry, while irregular past-tense forms (e.g., the word "went") are handled by a word storage system that is mediated by temporal lobe circuitry. In support of this view, it has been claimed that overgeneralization errors are common in patients with temporal lobe involvement (including Alzheimer's patients and Wernicke's aphasics). Our results for adult aphasics provide no support for this view.

Treating morphological errors as a whole (including omissions and substitutions of bound morphemes), we conducted an Age $\times$ Lesion Group analysis of variance on the proportion of all propositions containing a morphological error. This analysis yielded a large and significant main effect of age, but the main effect of lesion group and the age by lesion group interaction both failed to reach significance. Hence it seems that this is an area in which developmental effects predominate over specific or general effects of brain injury. However, separate one-way analyses of variance did yield a significant main effect for adults, but no effect for children. For children, all paired comparisons failed to reach significance, reflecting mean morphological error rates of $4.6 \%$ in LHD, $4.7 \%$ in normals, and $6 \%$ in RHD. For adults, the LHD/RHD comparison missed significance $(p<.10)$, although morphological errors were numerically more common in LHD (3.8\%) than RHD $(0.8 \%)$, compared with an exceedingly small rate of $0.2 \%$ in adult normals. The difference between LHD and normal was significant, but the difference between RHD and normal just missed significance $(p<.06)$.

A breakdown of LHD patients into aphasia subtypes (Table 3, Fig. 8a) shows that morphological errors rates vary markedly, from a low of $0.7 \%$ in Wernicke's aphasics to a high of $11.7 \%$ in Broca's aphasics. Detailed examination of the various subtypes that go into these scores indicate that the vast majority of these errors involve omission of an obligatory inflection (e.g., "kick" instead of "kicks"), rather than morphological 
substitutions or additions (e.g., "kicks" instead of "kick", or "wented" instead of "went"). This result is in large measure an artifact of English: morphological substitutions tend to be very rare in English in both children and aphasics, due to the impoverished nature of the English inflectional system. Consider, for example, a partial conjugation of the verb "eats" in the simple indicative: "I eat, you eat, she eats, we eat, youall eat, they eat." The only contrast here is between the zero form "eat" the third-person singular form "eats". The equivalent conjugation in Italian would be the following: "Io mangio, tu mangi, lei mangia, noi mangiamo, voi mangiate, loro mangiano," with different suffixes on every form. In fact, errors of morphological substitution are often observed in fluent Wernicke's aphasics who are native speakers of a richly inflected languages like Italian, German, Hungarian or Turkish (Bates, 1991; Pick, 1913/1973). Because omission errors are the most likely form of morphological error in English, we should not be surprised that such errors are more common in the slow and effortful speech of nonfluent Broca's aphasics.

Finally, we compared adults and children directly within each lesion group, on both raw proportion scores and $z$ scores (which were possible for morphological errors, because the mean and standard deviation for normal adults was above zero, albeit very small). For normals, there was a significant difference reflecting many more morphological errors among children. This difference approached significance in the same direction for RHD $(p<.09)$, but was nonsignificant for children vs adults with LHD. Another way of putting this is that left-hemisphere injury in adults results in error rates similar to those observed in normal children. When $z$ scores were used, we uncovered a very large disadvantage for LHD adults compared with LHD children, reflecting a mean $z$ score of +7.11 in LHD adults vs -.018 in LHD children. The corresponding comparison between RHD adults (mean $\mathrm{z}=+1.19$ ) and RHD children (mean $\mathrm{z}=+.37$ ) was not significant.

Lexical errors. This category reflects errors of substitution or addition involving content words, as well as production of nonwords or "neologisms." For children, scores averaged around one lexical error per proposition; for adults, the range was very large, from absolutely no lexical errors among our normal adults to highs of $12.8 \%$ and $8.9 \%$, respectively, for Broca's and Wernicke's aphasics (see Table 3 and Fig. 8a for details). In group comparisons, statistical results were consistent with the patterns that we have obtained in all the previous analyses: absence of any lesion group effects in children compared with high variability and marked lesion effects in brain-injured adults.

This is one of the areas that reveals classic differences between fluent and nonfluent adult aphasics. Recall that Wernicke's aphasics produced relatively few morphological or omission errors, compared with the large numbers produced by Broca's aphasics.
However, Wernicke's were a close second to Broca's aphasics on lexical substitution errors, one of the hallmark symptoms of severe fluent aphasics. Although there are only three patients in each of these two groups, we attempted a group by error type multivariate analysis of variance to determine whether the patterning was significantly different for omission vs lexical errors. The comparison did yield a significant group by error type interaction $(p<.05)$, which is not surprising but does provide a further validation of the biographical interview method as a means of assessing differences among adult aphasia subtypes.

Because there were no errors (and hence no variance) for adult controls, a full Age by Lesion Group analysis could not be conducted. In a separate threeway Lesion Group analysis for children, there was again no effect of lesion group for children $(p<.16)$. In a paired comparison for adults, the LHD/RHD difference just missed significance $(p<.054)$.

Because normal adults produced absolutely no lexical errors in this situation, it was impossible to construct $z$ scores for adult patients. However, the data in Table 3 indicate that lexical errors do occur in all of the adult subgroups, including nonaphasic patients with LHD (1.5\% of propositions) as well as nonaphasic patients with RHD ( $0.7 \%$ of propositions).

Finally, although we could not compare adults and children on age-based $z$ scores, paired comparisons on raw proportion scores indicate that LHD children produce significantly fewer lexical errors than LHD adults. The difference between adults with RHD and children with RHD missed significance $(p<.09)$, but the trend was in the same direction that we saw in normals (i.e., more lexical errors in children). Once again, then, we find that left-hemisphere injury has much more serious effects on adults than it has on children.

To summarize across results of error analyses, we once again find no significant differences between children with LHD vs RHD on total errors or on any subcategory. This is, however, one of the few measures in which brain-injured children as a group perform significantly below their normal age-matched controls, a result that is due primarily to morphological errors. Another way of putting this is that brain-injured children are lagging slightly behind their normal peers in grammatical development, producing error rates and error patterns similar to those observed in the youngest of our normal controls. This lag is relatively small, however, reflecting age-based $z$ scores under one standard deviation from the normal mean in all categories, and it is not serious enough for the braininjured children to qualify for a diagnosis of language impairment.

These results for children contrast markedly with those for brain-injured adults. Errors are exceedingly rare in adult normals, and the few that do occur are entirely within the category of morphological errors, averaging 2/1000 propositions. Errors were far more 
common in all categories among brain-injured adults, including RHD and nonaphasic patients with LHD. However, a detailed look at the specific error categories revealed classic patterns among the more severe aphasic subgroups, with nonfluent Broca's patients erring primarily by omission (including omission of bound inflections) while fluent Wernicke's aphasics are more prone to errors of substitution (especially substitution of content words). These classic aphasia patterns do not appear in children with comparable injuries.

\section{SUMMARY AND CONCLUSION}

The results that we have just reviewed represent the first systematic comparison of children and adults with comparable forms of left- or right-hemisphere injury on measures of language production in free speech. Because language development is a moving target, with changes occurring across the lifespan, brain-injured children and adults were compared not only on raw scores and/or proportion scores for our various measures, but on $z$ scores based on performance by age-matched controls. The following five conclusions emerge from these comparisons:

1. Normal outcomes following early focal brain injury. Children with unilateral brain injury performed within the normal or low-normal range on all comparisons (i.e., less than one standard deviation from the normal mean), and they differed significantly from their age-matched controls on only a handful of measures (i.e., lower scores in lexical diversity, and higher error rates, especially in the category of morphological errors).

2. Absence of specific lesion effects in 5- to 8-yearold children with early focal brain injury. We found absolutely no evidence for a significant difference between children with LHD and children with RHD, on any measure. There was one measure (number of word types) that yielded a significant difference between LHD and controls, while the difference between RHD and controls just missed significance. If we were to follow an analytic strategy adopted in early studies of children with focal brain injury, we might conclude that LHD show a deficit that is not apparent in RHD. However, because the direct comparison between lesion groups did not even approach significance, it should be clear why this strategy would be misleading. We note in this regard that LHD children were numerically behind RHD on some measures (e.g., measures of amount of speech) but they were numerically ahead of RHD children on others (e.g., the various error categories, where RHD produced a larger number of errors). In short, there is nothing here to support the idea that children with left-hemisphere damage lag behind children with right-hemisphere damage on any aspect of language production.

3. Classic effects of lesion side in brain-injured adults. In contrast with these nonresults for children, we found large and varied effects of left- vs right- hemisphere damage in adults, including classic effects associated with the different aphasia subgroups (e.g., low syntactic diversity and high error rates in severely aphasic patients; more omission and morphological errors and high rates of ellipsis in Broca's aphasics; a higher proportion of lexical subsitutions and neologisms in fluent Wernicke's aphasics). Adults with LHD performed below adults with RHD on most measures. When LHD/RHD comparisons failed to reach significance, this was usually due to high variance in the LHD group, reflecting well-known differences between fluent and nonfluent aphasia subtypes.

4. Disinhibition in nonaphasic patients with unilateral injury. In addition to classic aphasia symptoms, performance in the open-ended interview situation revealed selective problems in RHD patients and some nonaphasic patients with LHD that would not be apparent in highly structured language tests. In particular, the nonaphasic patients talked twice as much as anyone else, a disinhibited and garrulous approach to the interview situation that involved (as we saw in detailed analyses) relatively empty speech characterized by high ratios of complex syntactic tokens but relatively low ratios of complex syntactic types. It is also worth noting that the nonaphasic patients produced higher than normal error rates, due primarily to an increase in morphological errors that are not observed in normals. This latter finding provides support for a hypothesis raised by several investigators (Bates, Appelbaum \& Allard, 1991; Bates \& Wulfeck, 1989; Kolk \& Heesch-, en, 1990, 1992), who have suggested that substitution errors (especially errors of morphological substitution) may reflect a speed/accuracy trade-off. That is, when a patient is talking at abnormally slow speeds, errors of omission are the most likely error type; when the patient talks at an abnormally high speed (or a higher speed than his/her central processing capacity can bear), then errors of commission are the most likely error type. In this framework, aphasic errors can be viewed as a by-product of normal organization subjected to abnormal stress and abnormal timing (Dell, Schwartz, Martin, Saffran, \& Gagnon, 1998).

5. Reliable child advantage when children and adults with LHD are compared directly using z scores. Adults talk more than children, and they try to convey relatively sophisticated ideas in a biographical interview. This is true even for many adult aphasics, who attempt to produce speech that is relatively high in propositional complexity despite high error rates and difficulty mounting complex syntactic constructions. For this reason, a direct comparison of adults and children on raw scores can be quite misleading. When adults and children were compared directly using agerelated $z$ scores, the differential effects of left-hemisphere damage on children and adults became inescapably clear. The LHD children (like the RHD children) had $z$ scores within the normal range for their age. The LHD adults had $z$ scores reflecting moderate to 
severe aphasia in many cases, including $z$ scores that were more than 200 standard deviations above the normal adult mean for total errors per proposition in our small-group LHD patients with Broca's aphasia. Headon comparisons of $z$ scores for children and adults with LHD were significant in most of our analyses, reflecting in every case a significant advantage for children over adults with comparable injuries.

We have quantified a conclusion that has been known for some time among clinicians, based on informal comparisons. However, in part because of early studies claiming that children with LHD display deficits that are not apparent in RHD (e.g., Dennis \& Whitaker, 1976, 1977), one occasionally finds references in textbooks suggesting that early left-hemisphere damage always leaves a signature deficit, however slight, that is not seen in children with damage to the other hemisphere. This belief persists despite mounting evidence to the contrary, because it fits so well with the mental-organ view that has dominated much of our thinking about brain organization for language in the last century. If early left-hemisphere injury does not lead to deleterious outcomes (or, at least, worse outcomes than early right-hemisphere injury), then how can we explain the overwhelming evidence that LHD leads to aphasia in adults while RHD does not (or does so only in very rare cases of cross-dominance)?

A potential answer to this question comes from other studies by our research group, in which we have shown that there are significant effects of lesion side and site in the first stages of language development. Although the lesion-symptom correlations that we observe do not always match the correlations observed in adults, they may provide insights into the initial conditions that lead to left-hemisphere specialization for language under normal conditions (Bates et al., 1997; Reilly et al., 1998; Thal et al., 1991; Vicari et al., 2000). For example, we find that early delays in word comprehension and symbolic gesture are actually somewhat more common in children with RHD, but this bias has only been observed in our laboratories in the period between 10 and 20 months of age. In contrast, deficits in expressive vocabulary and expressive grammar are more common in children with LHD, a difference that persists across the period from 10 months of age to approximately 5-6 years. However, this effect seems to be due primarily to deficits involving the left temporal lobe, i.e., an area that is supposed to have more to do with perception and much less to do with production. Why do these effects look so different in children than adults?

In various reviews of this work, we have pointed out that learning to talk for the first time is a very different process from the fluent use of language in comprehension and production by adults. Perhaps for that reason, children who are breaking into language for the first time draw upon resources that are appropriate and important for learning, but may be less important for fluent language use by adults. For example, in order to achieve the kind of multimodal integration of information that is required to break into the linguistic system and figure out what words mean for the first time, children may have to draw on resources that are better represented in the right hemisphere On the other hand, when children are struggling to produce words for the first time, reproducing familiar sounds in their input language, they have to extract more perceptual detail from the input than they need for the simpler process of word recognition. In normal children who have not suffered early focal brain injury, resources in the temporal regions of the left hemisphere may be particularly well suited to the extraction of perceptual detail, and hence may prove more important for word and sentence production. In normal children, this initial pattern of heavy reliance on left perisylvian cortex may eventually stabilize into the familiar ipsilateral circuitry for language processing that we observe in the left hemisphere of normal adults. In children who have suffered early injuries to the same brain regions, language acquisition (especially language production) may be delayed because less efficient circuits have been drafted into use. However, it seems clear from the present study and others like it that the problem has been largely solved by 5-8 years of age.

It is clear from the present study and other studies in our laboratory that differences between LHD and RHD on language tasks have disappeared or somehow gone underground by 5-8 years of age. Indeed, in the open-ended interview situation adopted in the present study, we find very little evidence that early focal injury has exacted a cost of any kind in language production. However, as we have already noted, this kind of openended task allows our participants a lot of freedom to choose what they want to say, and how they want to say it. When children are forced to respond in more structured and demanding tasks, we tend to find larger differences between brain-injured children and normal controls. In language production, results of this kind include the production of tag questions (Weckerly, Contreras, Wulfeck, \& Reilly, 1999; cf. Dennis, Sugar, $\&$ Whitaker, 1982), elicitation of the past tense (Marchman, Wulfeck, \& Ellis Weismer, 1999), and multifaceted studies of narrative discourse (Losh, Reilly, \& Bates, 1996; Reilly et al., 1998). In language comprehension, results extend to comprehension of complex syntax (Dick, Wulfeck, Bates, Naucler, \& Dronkers, 1999), and other on-line language tasks that are sensitive to the temporal microstructure of language processing (von Berger, Wulfeck, Bates, \& Fink, 1996; Wulfeck, 1993). On all of these sensitive language measures as well as other studies using standardized tests (Ballantyne \& Trauner, 1999), children with early unilateral brain injury tend to perform significantly below normal controls, although their performance is better than that of children with specific language impairment of unknown origin (which is not, as far as 
anyone has been able to tell, associated with frank lefthemisphere injuries). Most important for our purposes here, none of these studies have revealed differential effects of left- vs right-hemisphere damage in the congenital focal lesion population. Nor is there any reason to believe that such a difference will appear later, when language development has stabilized. Our own studies have included children tested up to 14-16 years of age, and there is no sign that a hemispheric difference is about to emerge. Furthermore, follow-up studies of adults with a history of early focal brain injury have generally failed to identify specific effects of lesion side of site (Rasmussen \& Milner, 1977).

Why are our results (in the present study and the others just reviewed) so different from the positive effects of side of injury reported in earlier studies of language outcomes following unilateral injury (e.g., Woods \& Teuber, 1976; Riva \& Cazzaniga, 1986, Riva et al., 1986; Dennis \& Whitaker, 1976, 1977)? We have dealt with this issue in some detail in recent reviews (Bates \& Roe, 2001; Bates, Vicari \& Trauner, 1999). For present purposes, we note that methodological differences may be responsible for the apparent conflict. First, although we have looked at complex syntax in some of our studies (in both comprehension and production) and found no lesion site effects when children were tested after 5-6 years of age, we did not use the same measures of syntax employed by Dennis and Whitaker, or by Riva et al. Second, there are some potentially important differences in the populations tested across these studies. Some of the earlier studies included children who varied in age of onset and/or etiology. For example, Riva et al. studies of language outcomes following perinatal stroke included children with a wider range of lesion onset times than the congenital population in our studies. The Dennis and Whitaker studies focused on small samples of children who had undergone hemispherectomies. The pathology leading to those hemispherectomies was congenital, and the surgery in all the cases studied was quite early (before 4 months of age), so age of onset is comparable between their studies and ours. However, the underlying pathology is still quite different, and the tissue loss following hemispherectomy is of course far more extensive than the lesions in most of our congenital stroke cases. Finally, there are occasional differences across these studies in the statistical methods employed (e.g., whether children with LHD vs RHD were compared directly, using inferential statistics, or compared indirectly, sometimes using separate controls for each lesion group-for a discussion of these analytic issues, see Bishop, 1983). It is worth noting in this regard that our results for language outcomes in children with congenital, unilateral strokes are quite compatible with reports by other investigators for the same population, using methods similar to ours (e.g., Vargha-Khadem et al., 1992, 1994).
In short, we conclude that evidence for plastic reorganization following early unilateral brain injury is compelling, at least within the domain of language. It shows up in a wide variety of tasks, and as we have shown here, it is particularly clear when children are compared directly with adults who have suffered comparable injuries. Something must be there at the beginning, some kind of difference between the two hemispheres that triggers the familiar pattern of lefthemisphere dominance for language in normal adults. However, our evidence suggests that this "something" is not a full-blown organ for language, laid out in a specific site. Instead, the starting points that lead to asymmetrical organization for language may involve relatively soft biases in information processing that can be overcome.

\section{REFERENCES}

Aram, D.M. (1988). Language sequelae of unilateral brain lesions in children. In F. Plum (Ed.), Language, communication, and the brain (pp. 171197). New York: Raven Press.

Aram, D.M. (1992). Brain injury and language impairment in childhood. In P. Fletcher \& D. Hall (Eds.), Specific speech and language disorders in children. London: Whurr Publishers.

Aram, D.M., Ekelman, B., \& Whitaker, H. (1985). Lexical retrieval in left and right brain-lesioned children. Brain and Language, 28, 61-87.

Aram, D.M., Ekelman, B., Rose, D., \& Whitaker, H. (1985). Verbal and cognitive sequelae following unilateral lesions acquired in early childhood. Journal of Clinical and Experimental Neuropsychology, 7, 55-78.

Ballantyne A.O., Scarvie, K.M., \& Trauner, D.A. (1994). Verbal and performance IQ patterns in children after perinatal stroke. Developmental Neuropsychology, 10, 39-50.

Ballantyne, A.O., \& Trauner, D.A. (1999). Neuropsychological profiles of infants and children with early focal brain damage. JINS, 5, 145.

Bates, E. (Ed.). (1991). Special issue: Cross-linguistic studies of aphasia. Brain and Language, 41(2).

Bates, E. (1999). Plasticity, localization and language development. In S. Broman \& J.M. Fletcher (Eds.), The changing nervous system: Neurobehavioral consequences of early brain disorders (pp. 214-253). New York: Oxford University Press.

Bates, E., Appelbaum, M., \& Allard, L. (1991). Statistical constraints on the use of single cases in neuropsychological research. Brain and Language, 40, 295-329.

Bates, E., Bretherton, I., \& Snyder, L. (1988). From first words to grammar: Individual differences and dissociable mechanisms. New York: Cambridge University Press. 
Bates, E., \& Roe, K. (2001). Language development in children with unilateral brain injury. In C.A. Nelson \& M. Luciana (Eds.), Handbook of developmental cognitive neuroscience (pp. 281-307). Cambridge, MA: MIT Press.

Bates, E., Thal, D., Finlay, B.L., \& Clancy, B. (in press). Early language development and its neural correlates. To appear in F. Boller \& J. Grafman (Series Eds.) \& I. Rapin \& S. Segalowitz (Vol. Eds.), Handbook of neuropsychology, Vol. 7: Child neurology (2nd ed.). Amsterdam: Elsevier.

Bates, E., Thal, D., Trauner, D., Fenson, J., Aram, D., Eisele, J., \& Nass, R. (1997). From first words to grammar in children with focal brain injury. Developmental Neuropsychology, 13, 447-476.

Bates, E., Vicari, S., \& Trauner, D. (1999). Neural mediation of language development: Perspectives from lesion studies of infants and children. In $\mathrm{H}$. Tager-Flusberg (Ed.), Neurodevelopmental disorders (pp. 533-581). Cambridge, MA: MIT Press.

Bates, E., \& Wulfeck, B. (1989). Comparing approaches to comparative aphasiology. Aphasiology, 3, 161-168.

Bates, E., Wulfeck, B., \& MacWhinney, B. (1991). Crosslinguistic research in aphasia: An overview. Brain and Language, 41, 123-148.

Bernhardt, M., 1897. In Nothnagel. Spezielle Pathoogie und Therapie, 9, Part 2. Vienna.

Bishop, D.V.M. (1983). Linguistic impairment after left hemidecortication for infantile hemiplegia? A reappraisal. Quarterly Journal of Experimental Psychology, 35A, 199-207.

Bishop, D.V.M. (1997). Uncommon understanding: Development and disorders of comprehension in children. Hove, UK: Psychology Press.

Caplan, D., \& Hildebrandt, N. (1988). Disorders of syntactic comprehension. Cambridge, MA: MIT Press.

Chen, S., \& Bates, E. (1998). The dissociation between nouns and verbs in Broca's and Wernicke's aphasics: Evidence from Chinese. Special issue on Chinese aphasia, Aphasiology, 12, 5-36.

Cotard, J., 1868. Etude sur l'atophie partielle du cerveau. Thèse de Paris.

Deacon, T. (1997). The symbolic species: The coevolution of language and the brain. New York: Norton.

Dell, G.S., Schwartz, M.F., Martin, N., Saffran, E.M., \& Gagnon, D. A. (1997). Lexical access in aphasic and nonaphasic speakers. Psychological Review, 104, 801-838.

Dennis, M., \& Whitaker, H. (1976). Language acquisition following hemidecortication: Linguistic superiority of the left over the right hemisphere. Brain and Language, 3, 404-433.
Dennis, M., \& Whitaker, H. (1977). Hemispheric equipotentiality and language acquisition. In S.J. Segalowitz \& F.A. Gruber, (Eds.), Language development and neurological theory (pp. 93-106). New York: Academic Press.

Dennis, M., Sugar, J., \& Whitaker, H. (1982). The acquisition of tag questions. Child Development, $53,1254-1257$.

Dick, F., Wulfeck, B., Bates, E., Saltzman, D., Naucler, N., \& Dronkers, N. (1999). Interpretation of complex syntax in aphasic adults and children with focal lesions or specific language impairment (Abstract). Brain and Language, 69, 335-336.

Eisele, J., \& Aram, D. (1995). Lexical and grammatical development in children with early hemisphere damage: A cross-sectional view from birth to adolescence. In P. Fletcher \& B. MacWhinney (Eds.), The handbook of child language (pp. 664689). Oxford: Basil Blackwell.

Elman, J.L., Bates, E., Johnson, M., Karmiloff-Smith, A., Parisi, D., \& Plunkett, K. (1996). Rethinking innateness: A connectionist perspective on development. Cambridge, MA: MIT Press/ Bradford Books [paperback edition published 1998].

Feldman, H., Holland, A., Kemp, S., \& Janosky, J. (1992). Language development after unilateral brain injury. Brain and Language, 42, 89-102.

Fodor, J.A. (1983). The modularity of mind: An essay on faculty psychology. Cambridge, MA: MIT Press.

Goodglass, H. (1993). Understanding aphasia. San Diego: Academic Press.

Johnson, M.H. (1997). Developmental cognitive neuroscience: An introduction. Cambridge, MA: Blackwell Publishers.

Kempler, D., van Lancker, D., Marchman, V., \& Bates, E. (1999). Idiom comprehension in children and adults with unilateral brain damage. Developmental Neuropsychology, 15, 327-349.

Kennard, M. (1936). Age and other factors in motor recovery from precentral lesions in monkeys. American Journal of Physiology, 115, 138-146.

Kolb, B. (1999). Synaptic plasticity and the organization of behaviour after early and late brain injury. Canadian Journal of Experimental Psychology, 53, 62-76.

Kolb, B., \& Whishaw, I. Q. (1998). Brain plasticity and behavior. Annual Review of Psychology, 49, 43-64.

Kolk, H. (1985). Telegraphic speech and ellipsis. Paper presented at the Conference on Crosslinguistic Studies of Grammatical Processing in Aphasia. Royaumont Conference Center, Paris.

Kolk, H., \& Heeschen, C. (1990). Adaptation symptoms and impairment symptoms in Broca's aphasia. Aphasiology, 4, 221-231. 
Kolk, H., \& Heeschen, C. (1992). Agrammatism, paragrammatism and the management of language. Language and Cognitive Processes, 7, 89-129.

Kuhl, P.K. (1993). Effects of linguistic experience in the first half-year of life: Implication for a theory of infant speech development. In D. de BoyssonBardies et al. (Eds.), Developmental neurocognition: Speech and face processing in the first year of life. Dordrecht: Kluwer.

Kuhl, P.K., Williams, K.A., Lacerda, F., Stevens, K.N., \& Lindblom, B. (1992). Linguistic experiences alter phonetic perception in infants by 6 months of age. Science, 255, 606-608.

Losh, M., Reilly, J.S., \& Bates, E. (1996, June). Language development: Neural plasticity in children with early focal brain injury. Poster session presented at the 8th Annual Meeting of the American Psychological Association, San Francisco.

MacWhinney, B., \& Snow, C. (1985). The child language data exchange system. Journal of Child Language, 12, 271-296.

Marchman, V. (1993). Constraints on plasticity in a connectionist model of the English past tense. Journal of Cognitive Neuroscience, 5, 215-234.

Marchman, V., Bates, E., Burkhardt, A., \& Good, A. (1991). Functional constraints on the acquisition of the passive: Toward a model of the competence to perform. First Language, 11, 65-92.

Marchman, V., Wulfeck, B., \& Ellis Weismer, S. (1999). Productive use of English past tense morphology in children with SLI and normal language. Journal of Speech, Language, and Hearing Research, 42, 206-219.

Molfese, D.L., \& Segalowitz, S.J. (1988). Brain lateralization in children: Developmental implications. New York: Guilford Press.

Nass, R. (in press). Plasticity: Extent and limits. To appear in F. Boller \& J. Grafman (Series Eds.), \& I. Rapin \& S. Segalowitz (Vol. Eds.), Handbook of neuropsychology, Vol. 7: Child neurology (2nd ed.). Amsterdam: Elsevier.

Newmeyer, F.J. (1997). Genetic dysphasia and linguistic theory. Journal of Neurolinguistics, 10, 4773.

O'Neill , Y.V. (1980). Speech and speech disorders in Western thought before 1600. Westport, CT: Greenwood Press.

Pick, A. (1973). Aphasia. (J. Brown, Ed. \& Trans.) Springfield, IL: Charles C. Thomas. (Original work published 1913).

Pinker, S. (1991). Rules of language. Science, 253, 530-535.

Pinker, S. (1994). The language instinct: How the mind creates language. New York: William Morrow.
Quartz, S.R., \& Sejnowski, T.J. (1994). Beyond modularity: Neural evidence for constructivist principles in development. The Behavioral and Brain Sciences, 17, 725-726.

Quartz, S.R., \& Sejnowski, T.J. (1997). The neural basis of cognitive development: A constructivist manifesto. The Behavioral and Brain Sciences, 20, 537.

Rasmussen, T., \& Milner, B. (1977). The role of early left brain injury in determining lateralization of cerebral speech functions. Annals of the New York Academy of Sciences, 229, 355-369.

Reilly, J., Bates, E. \& Marchman, V. (1998). Narrative discourse in children with early focal brain injury. In M. Dennis (Ed.), Special issue, Discourse in children with anomalous brain development or acquired brain injury. Brain and Language, 61, 335-375.

Rice, M. (Ed.). (1996). Toward a genetics of language. Mahwah, NJ: Erlbaum.

Riva, D., \& Cazzaniga, L. (1986). Late effects of unilateral brain lesions before and after the first year of life. Neuropsychologia, 24, 423-428.

Riva, D., Cazzaniga, L., Pantaleoni, C., Milani, N., \& Fedrizzi, E. (1986). Acute hemiplegia in childhood: The neuropsychological prognosis. Journal of Pediatric Neurosciences, 2, 239-250.

Stein, D.G. (1988). Development and plasticity in the CNS : Organismic and environmental influences. Worcester, MA: Clark University Press.

Stiles, J., Bates, E., Thal, D., Trauner, D., \& Reilly, J. (1998). Linguistic, cognitive and affective development in children with pre- and perinatal focal brain injury: A ten-year overview from the San Diego longitudinal project. In C. Rovee-Collier, L. Lipsitt \& H. Hayne (Eds.), Advances in infancy research (pp. 131-163). Norwood, NJ: Ablex.

Thal, D., Marchman, V., Stiles, J., Aram, D., Trauner, D., Nass, R. \& Bates, E. (1991). Early lexical development in children with focal brain injury. Brain and Language, 40, 491-527.

Ullman, M., Corkin, S., Coppola, M., Hickok, G., Growdon, J.H., Koroshetz, W.J., \& Pinker, S. (1997). A neural dissociation within language: Evidence that the mental dictionary is part of declarative memory, and that grammatical rules are processed by procedural system. Journal of Cognitive Neuroscience, 9, 266-276.

Vargha-Khadem, F., Isaacs, E., \& Muter, V. (1994). A review of cognitive outcome after unilateral lesions sustained during childhood. Journal of Child Neurology, 9 (Suppl), 2S67-2S73.

Vargha-Khadem, F., Isaacs, E., van der Werf, S., Robb, S., \& Wilson, J. (1992). Development of intelligence and memory in children with hemiplegic cerebral palsy: The deleterious consequences of early seizures. Brain, 115, 315-329. 
Vicari, S., Albertoni, A., Chilosi, A., Cipriani, P., Cioni, G. \& Bates, E. (2000). Plasticity and reorganization during language development in children with early brain injury. Cortex, 36, 31-46.

Von Berger, E., Wulfeck, B., Bates, E., \& Fink, N. (1996). Developmental changes in real-time sentence processing. First Language, 16, 193-222.

Webster, M.J., Bachevalier, J., \& Ungerleider, L.G. (1995). Development and plasticity of visual memory circuits. In B. Julesz \& I. Kovacs (Eds.), Maturational windows and adult cortical plasticity: Is there reason for an optimistic view? Proceedings of the Santa Fe Institute Studies in the Sciences of Complexity, Vol. 23 (pp. 73-86).

Reading, MA: Addison-Wesley.
Weckerly, J., Contreras, R., Wulfeck, B., \& Reilly, B. (1999, June). The acquisition of tag questions in children with language impairment and children with early focal brain lesions. Poster presented at the 20th Annual Symposium on Research in Child Language Disorders, Madison, WI.

Witelson, S. F., \& Pallie, W. (1973). Left hemisphere specialization for language in the newborn: Neuroanatomical evidence of asymmetry. Brain, 96, 641-646.

Woods, B. T., \& Teuber, H. L. (1978). Changing patterns of childhood aphasia. Annals of Neurology, 3, 272-280.

Wulfeck, B. (1993). A reaction time study of grammaticality judgments in children. Journal of Speech and Hearing Research, 36, 1208-1215. 


\section{APPENDIX A: BIOGRAPHICAL INTERVIEW-CHILDREN}

\section{PURPOSE}

This procedure is intended to elicit free-speech narratives about the subject's personal history and experiences. The example questions are guidelines, phrased to encourage episodic narratives rather than general impressions/feelings. The goal is to get the child to talk. Nod and/or offer verbal reinforcements often.

\section{INSTRUCTIONS}

We're going to have lots of fun today playing with toys and telling stories. Stories are a good way of letting people know about things that happen to you or what kinds of things you like to do. If I ask you some questions, will you tell me some stories about your life and the things you like to do?

\section{EXAMPLE QUESTIONS}

1. Where do you live? How many brothers and sisters do you have? What are their names? Can you tell me a funny story about something that one of your brothers or sisters did?

2. Do you have any pets? What kind? What are their names? What do you like to do with them (e.g., play fetch, go for walks, etc.)? Tell me about one day when you did something fun with your pet.

3. What do you like to do on the weekends? Can you tell me about something interesting that you did last weekend?

4. Do you like to go places with your mother and/or father (grandma and/or grandpa)? Can you tell me about a place that you went (something that you did) with your mother and/or father that you liked very much? didn't like very much?

5. What is your favorite subject in school? Tell me about something that you did in school that you liked very much. that you did not like very much.

6. What do you like to do after school? Tell me about something fun that happened after school.

7. Do you have a best friend? What is his/her name? Tell me about something fun that you did with your best friend.

8. Do you ever watch TV/go to the movies? Which is your favorite? Tell me about something that happened on one on your favorite TV shows/in your favorite movie. What is your favorite story book? Can you tell me a little about it? 


\section{APPENDIX B: BIOGRAPHICAL INTERVIEW WITH ADULTS}

The biographical interview should be administered at the beginning of the subject's first testing session. It is designed to elicit as much free conversation as possible. Encourage patient to speak for at least 10 minutes, if possible. Try to minimize use of "yes" - "no" questions.

\section{BIOGRAPHICAL INTERVIEW}

\section{OPENING/GREETING}

1. Hello M(r., rs., iss) _ How are you today?

2. What do you think of this (sunny, rainy, cloudy, cold) day?

3. Can you tell me where you live, come from, your address?

4. How did you get here today?

\section{$\underline{\text { FAMILY }}$}

5. Do you live with anyone? Are you married? What is your wife's/husband's name?

6. Do you have any children?

7. Tell me about your family.

8. What does your daughter/son do?

9. Where does he/she live?

10. Do you have any grandchildren?

11. Tell me what you do with them.

\section{CURRENT EVENTS}

12. Ask some general questions pertaining to local, national news, TV shows, or other familiar facts. This must be appropriate to the patient's educational or social background.

\section{$\underline{\text { PERSONAL HISTORY }}$}

13. What did you do before you became ill?

14. Where did you work?

15. Where were you born?

16. Where did you grow up? 
17. What language(s) did you speak as a child/adult? Dialects?

18. Did you go to high school? College?

19. Where were your parents born?

20. What did your father/mother do?

21. Do you have sisters/brothers?

22. Tell me where they live. 


\section{APPENDIX C: CATEGORIES FOR CODING OF COMPLEX SYNTAX}

Coordinates

1. And And

2. $\quad$ Or

3. But

Clefts

4.

5 .

Complex Noun Phrases

$6 . \quad$ Relative clauses: with relative pronoun (who, where, that)

$7 . \quad$ Relative clauses: without relative pronoun

8. Headless relatives (I didn't know what to do.)

$9 . \quad$ Sentential NP's

First subject of clause (How to play soccer is the topic today.)

10. ___ Non-finite clauses: infinitival (the last train to arrive)

11. Non-finite clauses: participial

Complex Verb Phrases

12. That complements (I know that...)

13. In_ Ininitival complements (try to go...)

14. Gerundive complements (keep trying)

15._Dialogue (text between quotations)

Adverbials

16. Subordinate: with finite verbs (when, how, because)

17. Subordinate: verbless clauses (When ripe, the berries are picked.)

18. N__ Non-finite adverbial clauses: present participles (After eating the cake, she felt ill)

19. __ Non-finite adverbial clauses: past participles (Seen from afar, the car looks small.)

Passives

20. ___ Be Passives

full BE passives (with "by" phrases)

21. Got Passives truncated BE passives (without "by" phrases)

Total

full GOT passives with "by" phrases truncated GOT passives without "by" phrases 


\section{APPENDIX D: CATEGORIES FOR ERROR CODING}

1. Omission Errors

Total

2. Morphological Errors

Total

a. ___ Pronoun Case Error (him lost it, us do it)

b. Plural Agreement Zero form (two shoe - plural morpheme absent when it should be there) Non-zero form (one shoes - plural morpheme present when it shouldn't be)

c. Verb Tense Errors - only when past, present, or future tense is clearly indicated Zero form (he fall there once) Non-zero form (he cooked tomorrow)

d. Verb Number Agreement Zero form (he kick the ball - morpheme absent when it should be there.) Non-zero form (I kicks the ball - morpheme present when it shouldn't be there)

e. __ Prepositional Errors

f. __ Overregularization of Morphological Rules (falled, goed,)

3. Lexical Errors

Total

a. Insertion or addition of a whole word

b. Paraphasias

Wrong word: word (e.g. "hog" instead of "dog")

Wrong word: non-word (e.g. "gog" instead of "dog") 
Table 1: Neurological Information for Child Patients

\begin{tabular}{|c|c|c|c|c|c|c|}
\hline Subject \# & Age@test & Gender & $\begin{array}{l}\text { Lesion } \\
\text { Side }\end{array}$ & $\begin{array}{l}\text { Lobes } \\
\text { Involved* }\end{array}$ & $\begin{array}{l}\text { Cortical } \\
\text { Damage }\end{array}$ & $\begin{array}{l}\text { Subcort. } \\
\text { Damage }\end{array}$ \\
\hline 3001 & 6 & $\mathrm{M}$ & Left & FTPO & Yes & Yes \\
\hline 3002 & 8 & $\mathrm{M}$ & Left & FTPO & Yes & Yes \\
\hline 3004 & 7 & $\mathrm{M}$ & Left & $\mathrm{T}$ & n.a.** & Yes \\
\hline 3005 & 8 & $\bar{F}$ & Right & $\mathrm{PT}$ & No & Yes \\
\hline 3008 & 7 & $\mathrm{M}$ & Right & FP & Yes & Yes \\
\hline 3009 & 8 & $\mathrm{~F}$ & Left & $\mathrm{F}$ & Yes & Yes \\
\hline 3011 & 8 & $\bar{M}$ & Left & $\mathrm{F}$ & No & Yes \\
\hline 3012 & 5 & $\mathrm{M}$ & Left & $\mathrm{PO}$ & Yes & No \\
\hline 3016 & 8 & $\mathrm{M}$ & Left & FTP & Yes & Yes \\
\hline 3017 & 8 & $\bar{F}$ & Left & $\mathrm{T}$ & Yes & No \\
\hline 3018 & 8 & $\mathrm{M}$ & Left & $\mathrm{TP}$ & Yes & Yes \\
\hline 3020 & 8 & $\mathrm{~F}$ & Right & FTPO & Yes & Yes \\
\hline 3021 & 5 & $\mathrm{M}$ & Left & $\mathrm{P}$ & Yes & Yes \\
\hline 3022 & 6 & $\mathrm{M}$ & Right & FTPO & Yes & Yes \\
\hline 3032 & 8 & $\mathrm{~F}$ & Left & FTPO & Yes & Yes \\
\hline 3034 & 7 & $F$ & Right & FTP & Yes & Yes \\
\hline 3038 & 7 & $\bar{M}$ & Left & FTPO & Yes & Yes \\
\hline 3040 & 8 & $\mathrm{M}$ & Left & FTP & Yes & Yes \\
\hline 3044 & 5 & $\mathrm{M}$ & Right & FTPO & Yes & Yes \\
\hline 3045 & 6 & $\bar{F}$ & Left & basal ganglia & No & Yes \\
\hline 3047 & 5 & $\mathrm{M}$ & Left & TPO & Yes & Yes \\
\hline 3050 & 6 & $\mathrm{M}$ & Right & $\mathrm{P}$ & Yes & Yes \\
\hline 3051 & 5 & $\mathrm{M}$ & Right & $\mathrm{F}$ & Yes & No \\
\hline 3055 & 6 & $\bar{F}$ & Right & FTPO & Yes & Yes \\
\hline 3057 & 8 & $\mathrm{~F}$ & Left & $\mathrm{PO}$ & Yes & Yes \\
\hline 3059 & 5 & $\mathrm{~F}$ & Left & FTPO & Yes & Yes \\
\hline 3063 & 5 & $\mathrm{M}$ & Right & FTPO & Yes & Yes \\
\hline 3065 & 6 & $\mathrm{~F}$ & Left & FTPO & Yes & Yes \\
\hline 3070 & 7 & $\mathrm{M}$ & Right & $\mathrm{TP}$ & Yes & No \\
\hline 3810 & 6 & $\bar{F}$ & Left & $\mathrm{P}$ & n.a. & n.a. \\
\hline
\end{tabular}




\begin{tabular}{|l|l|l|l|l|l|l|}
\hline 3811 & 8 & M & Left & $\begin{array}{l}\text { porencephalic } \\
\text { cyst }\end{array}$ & n.a. & n.a. \\
\hline 3814 & 5 & F & Right & none & No & Yes \\
\hline 3817 & 5 & M & Right & F & n.a. & Yes \\
\hline 3823 & 8 & F & Left & n.a. & n.a. & n.a. \\
\hline 3825 & 8 & M & Left & FTP & Yes & Yes \\
\hline 3829 & 8 & M & Right & F & No & Yes \\
\hline 3834 & 7 & F & Left & FTPO & Yes & Yes \\
\hline 3847 & 6 & M & Left & atrophy & n.a. & n.a. \\
\hline
\end{tabular}

$* \mathrm{~F}=$ frontal lobe involvement; $\mathrm{T}$ = temporal lobe involvement; $\mathrm{P}=$ parietal lobe involvement; $\mathrm{O}=$ occipital lobe involvement

** n.a. = not available (cannot be determined from available radiological information) 
Table 2: Neurological and Demographic Information for Adult Patients

\begin{tabular}{|c|c|c|c|c|c|c|c|}
\hline ID \# & $\begin{array}{c}\text { Lesion } \\
\text { Onset Age }\end{array}$ & $\begin{array}{c}\text { Age at } \\
\text { Testing }\end{array}$ & Gender & $\begin{array}{c}\text { Years of } \\
\text { Education }\end{array}$ & Occupation & \begin{tabular}{|c}
$\begin{array}{c}\text { Side of } \\
\text { Lesion }\end{array}$ \\
\end{tabular} & $\begin{array}{c}\text { Aphasia } \\
\text { Classification }\end{array}$ \\
\hline 018 & 52 & 67 & $\bar{M}$ & 10 & $\begin{array}{c}\text { Electrical } \\
\text { Technician }\end{array}$ & Left & Broca \\
\hline 092 & 60 & 68 & $\bar{M}$ & 12 & $\begin{array}{l}\text { Cardroom } \\
\text { Floorman }\end{array}$ & $\overline{\text { Left }}$ & Broca \\
\hline 224 & 50 & 62 & $\mathrm{M}$ & 18 & Urban Planner & Left & Broca \\
\hline 244 & 44 & 48 & $\bar{M}$ & 18 & Teacher & Left & Wernicke \\
\hline 463 & 73 & 74 & $\bar{M}$ & 16 & Engineer & $\overline{\text { Left }}$ & Wernicke \\
\hline 757 & 44 & 49 & $\mathrm{~F}$ & 16 & Housewife & Left & Wernicke \\
\hline 419 & 67 & 75 & $\bar{M}$ & 12 & Auto Salesman & Left & Anomic \\
\hline 438 & 63 & 76 & $\bar{M}$ & 19 & $\begin{array}{l}\text { Corporate } \\
\text { President }\end{array}$ & Left & Anomic \\
\hline 557 & 58 & 66 & $\bar{M}$ & 20 & Geologist & Left & Anomic \\
\hline 653 & 70 & 79 & $\mathrm{M}$ & 14 & Salesman & Left & Anomic \\
\hline 773 & 68 & 70 & $\mathrm{~F}$ & 16 & $\begin{array}{c}\text { Teacher; } \\
\text { Accountant }\end{array}$ & Left & Anomic \\
\hline 680 & 65 & 68 & $\bar{M}$ & 14 & Retired & Left & Non-aphasic \\
\hline 810 & 75 & 83 & $\bar{M}$ & 18 & $\begin{array}{c}\text { School } \\
\text { Administrator }\end{array}$ & Left & Non-aphasic \\
\hline 813 & 80 & 83 & $\bar{M}$ & 18 & $\begin{array}{l}\text { Personnel } \\
\text { Officer }\end{array}$ & Left & Non-aphasic \\
\hline 721 & 46 & 50 & $\bar{M}$ & 13 & Road Grader & Right & Non-aphasic \\
\hline 765 & 59 & 63 & $\bar{M}$ & 8 & $\begin{array}{c}\text { Naval } \\
\text { Personnel }\end{array}$ & Right & Non-aphasic \\
\hline 818 & 53 & 56 & $\bar{M}$ & 17 & Engineer & Right & Non-aphasic \\
\hline 828 & 35 & 51 & $\bar{M}$ & 14 & Engineer & Right & Non-aphasic \\
\hline 829 & 75 & 79 & $\bar{M}$ & 8 & $\begin{array}{l}\text { Appliance } \\
\text { Salesman }\end{array}$ & Right & Non-aphasic \\
\hline 830 & 76 & 79 & $\mathrm{~F}$ & 15 & Cosmetologist & Right & Non-aphasic \\
\hline 831 & 48 & 50 & $\bar{F}$ & 16 & Teacher & Right & Non-aphasic \\
\hline
\end{tabular}


TABLE 3: DESCRIPTIVE STATISTICS FOR CHILD \& ADULT PATIENTS AND AGE-MATCHED CONTROLS (means, with standard errors below)

\begin{tabular}{|c|c|c|c|c|c|c|c|c|c|c|}
\hline & $\begin{array}{l}\text { Child } \\
\text { Normal } \\
n=38\end{array}$ & $\begin{array}{l}\text { Child } \\
\text { LHD } \\
\mathbf{n}=24\end{array}$ & $\begin{array}{l}\text { Child } \\
\text { RHD } \\
\text { n }=14\end{array}$ & $\begin{array}{l}\text { Adult } \\
\text { Normal } \\
n=12\end{array}$ & $\begin{array}{l}\text { Adult } \\
\text { LHD } \\
n=14\end{array}$ & $\begin{array}{l}\text { Adult } \\
\text { RHD } \\
\mathbf{n}=7\end{array}$ & $\begin{array}{c}\text { Broca's } \\
\text { Aphasic } \\
n=3\end{array}$ & $\begin{array}{l}\text { Wernicke's } \\
\text { Aphasic } \\
\mathbf{n}=\mathbf{3}\end{array}$ & $\begin{array}{c}\text { Anomic } \\
\text { Aphasic } \\
n=5\end{array}$ & $\begin{array}{l}\text { Non-Aphasic } \\
\text { LHD } \\
\mathbf{n}=\mathbf{3}\end{array}$ \\
\hline \# Utterances & $\begin{array}{l}59.8 \\
3.1\end{array}$ & $\begin{array}{l}52.6 \\
5.4\end{array}$ & $\begin{array}{l}53.3 \\
6.5\end{array}$ & $\begin{array}{l}65.0 \\
9.6\end{array}$ & $\begin{array}{l}95.1 \\
16.5\end{array}$ & $\begin{array}{c}141.3 \\
18.4\end{array}$ & $\begin{array}{l}90.0 \\
40.1\end{array}$ & $\begin{array}{l}95.0 \\
7.6\end{array}$ & $\begin{array}{l}63.4 \\
11.4\end{array}$ & $\begin{array}{l}153.0 \\
60.4\end{array}$ \\
\hline Z-Utterances & $-\ldots$ & $\begin{array}{c}-0.38 \\
.28\end{array}$ & $\begin{array}{c}-0.34 \\
.34\end{array}$ & $\ldots$ & $\begin{array}{c}+0.90 \\
.50\end{array}$ & $\begin{array}{l}+2.29 \\
.55\end{array}$ & $\begin{array}{c}+0.75 \\
1.21\end{array}$ & $\begin{array}{c}+0.90 \\
.23\end{array}$ & $\begin{array}{c}-0.05 \\
.34\end{array}$ & $\begin{array}{c}+2.64 \\
1.81\end{array}$ \\
\hline \# Word Types & $\begin{array}{c}137.7 \\
7.6\end{array}$ & $\begin{array}{c}105.9 \\
9.0\end{array}$ & $\begin{array}{c}115.2 \\
15.3\end{array}$ & $\begin{array}{l}202.2 \\
24.2\end{array}$ & $\begin{array}{l}188.6 \\
37.4\end{array}$ & $\begin{array}{l}356.4 \\
36.9\end{array}$ & $\begin{array}{l}130.7 \\
50.9\end{array}$ & $\begin{array}{l}166.0 \\
8.7\end{array}$ & $\begin{array}{l}128.2 \\
17.2\end{array}$ & $\begin{array}{l}369.7 \\
132.1\end{array}$ \\
\hline Z-Word Types & $-\ldots$ & $\begin{array}{c}-0.68 \\
.19\end{array}$ & $\begin{array}{c}-0.48 \\
.33\end{array}$ & $\ldots$ & $\begin{array}{c}-0.16 \\
.45\end{array}$ & $\begin{array}{c}+1.84 \\
.44\end{array}$ & $\begin{array}{l}-0.85 \\
.61\end{array}$ & $\begin{array}{l}-0.43 \\
.10\end{array}$ & $\begin{array}{l}-0.88 \\
.20\end{array}$ & $\begin{array}{l}2.00 \\
1.58\end{array}$ \\
\hline Word Types/Utt & $\begin{array}{l}2.36 \\
.09\end{array}$ & $\begin{array}{l}2.18 \\
.16\end{array}$ & $\begin{array}{l}2.26 \\
.20\end{array}$ & $\begin{array}{l}3.30 \\
.20\end{array}$ & $\begin{array}{l}2.08 \\
.20\end{array}$ & $\begin{array}{l}2.57 \\
.09\end{array}$ & $\begin{array}{l}1.69 \\
.72\end{array}$ & $\begin{array}{l}1.77 \\
.20\end{array}$ & $\begin{array}{l}2.18 \\
.29\end{array}$ & $\begin{array}{l}2.60 \\
0.34\end{array}$ \\
\hline Z-Word Types/Utt & $-\ldots$ & $\begin{array}{l}-0.33 \\
.29\end{array}$ & $\begin{array}{l}-0.18 \\
.36\end{array}$ & $\ldots$ & $\begin{array}{l}-1.76 \\
.29\end{array}$ & $\begin{array}{l}-1.05 \\
.13\end{array}$ & $\begin{array}{l}-2.30 \\
1.03\end{array}$ & $\begin{array}{l}-2.19 \\
.28\end{array}$ & $\begin{array}{l}-1.61 \\
.42\end{array}$ & $\begin{array}{l}-1.02 \\
.48\end{array}$ \\
\hline \# Word Tokens & $\begin{array}{l}358.6 \\
27.0\end{array}$ & $\begin{array}{l}285.0 \\
34.4\end{array}$ & $\begin{array}{l}337.1 \\
70.1\end{array}$ & $\begin{array}{l}525.0 \\
96.6\end{array}$ & $\begin{array}{l}598.8 \\
164.5\end{array}$ & $\begin{array}{l}1142.9 \\
175.2\end{array}$ & $\begin{array}{l}399.7 \\
175.4\end{array}$ & $\begin{array}{l}549.3 \\
90.8\end{array}$ & $\begin{array}{l}306.8 \\
68.3\end{array}$ & $\begin{array}{l}1334.0 \\
635.7\end{array}$ \\
\hline Z-Word Tokens & $-\ldots$ & $\begin{array}{l}-0.44 \\
.21\end{array}$ & $\begin{array}{l}-0.13 \\
.42\end{array}$ & $\ldots$ & $\begin{array}{c}+0.22 \\
.49\end{array}$ & $\begin{array}{c}+1.85 \\
.52\end{array}$ & $\begin{array}{l}-0.37 \\
.52\end{array}$ & $\begin{array}{l}+0.07 \\
.27\end{array}$ & $\begin{array}{l}-0.65 \\
.20\end{array}$ & $\begin{array}{l}+2.42 \\
1.9\end{array}$ \\
\hline Word Tokens/Utt & $\begin{array}{l}5.93 \\
.30\end{array}$ & $\begin{array}{l}5.50 \\
.45\end{array}$ & $\begin{array}{l}5.96 \\
.76\end{array}$ & $\begin{array}{l}7.76 \\
.48\end{array}$ & $\begin{array}{l}5.70 \\
.53\end{array}$ & $\begin{array}{l}8.03 \\
.31\end{array}$ & $\begin{array}{l}4.67 \\
1.15\end{array}$ & $\begin{array}{l}5.73 \\
.59\end{array}$ & $\begin{array}{l}4.80 \\
.72\end{array}$ & $\begin{array}{l}8.24 \\
.75\end{array}$ \\
\hline Z-Word Tokens/Ut & tt $\quad----$ & $\begin{array}{l}-.23 \\
.25\end{array}$ & $\begin{array}{l}.02 \\
.41\end{array}$ & $-\ldots$ & $\begin{array}{l}-1.24 \\
.32\end{array}$ & $\begin{array}{l}.16 \\
.19\end{array}$ & $\begin{array}{l}-1.87 \\
.69\end{array}$ & $\begin{array}{l}-1.22 \\
.36\end{array}$ & $\begin{array}{l}-1.79 \\
.43\end{array}$ & $\begin{array}{l}.29 \\
45\end{array}$ \\
\hline \# Morphemes & $\begin{array}{l}376.9 \\
29.3\end{array}$ & $\begin{array}{l}288.3 \\
35.1\end{array}$ & $\begin{array}{l}346.0 \\
72.1\end{array}$ & $\begin{array}{l}557.4 \\
94.9\end{array}$ & $\begin{array}{l}614.8 \\
170.8\end{array}$ & $\begin{array}{l}1247.3 \\
194.2\end{array}$ & $\begin{array}{l}417.7 \\
192.6\end{array}$ & $\begin{array}{l}554.7 \\
110.9\end{array}$ & $\begin{array}{l}304.6 \\
66.0\end{array}$ & $\begin{array}{l}1389.0 \\
648.2\end{array}$ \\
\hline
\end{tabular}


TABLE 3: DESCRIPTIVE STATISTICS FOR CHILD \& ADULT PATIENTS AND AGE-MATCHED CONTROLS (means, with standard errors below)

\begin{tabular}{|c|c|c|c|c|c|c|c|c|c|c|}
\hline & $\begin{array}{l}\text { Child } \\
\text { Normal } \\
\mathbf{n}=\mathbf{3 8}\end{array}$ & $\begin{array}{l}\text { Child } \\
\text { LHD } \\
\text { n = 24 }\end{array}$ & $\begin{array}{l}\text { Child } \\
\text { RHD } \\
\text { n }=14\end{array}$ & $\begin{array}{l}\text { Adult } \\
\text { Normal } \\
n=12\end{array}$ & $\begin{array}{l}\text { Adult } \\
\text { LHD } \\
n=14\end{array}$ & $\begin{array}{l}\text { Adult } \\
\text { RHD } \\
\mathbf{n}=7\end{array}$ & $\begin{array}{l}\text { Broca's } \\
\text { Aphasic } \\
\mathbf{n}=\mathbf{3}\end{array}$ & $\begin{array}{l}\text { Wernicke's } \\
\text { Aphasic } \\
\mathbf{n}=\mathbf{3}\end{array}$ & $\begin{array}{c}\text { Anomic } \\
\text { Aphasic } \\
n=5\end{array}$ & $\begin{array}{l}\text { Non-Aphasic } \\
\text { LHD } \\
\mathbf{n}=\mathbf{3}\end{array}$ \\
\hline Z-Morphemes & ---- & $\begin{array}{l}-0.49 \\
.20\end{array}$ & $\begin{array}{l}-0.17 \\
.40\end{array}$ & $\ldots$ & $\begin{array}{l}+0.17 \\
52\end{array}$ & $\begin{array}{l}+2.10 \\
.59\end{array}$ & $\begin{array}{l}-0.43 \\
.59\end{array}$ & $\begin{array}{l}-0.01 \\
.34\end{array}$ & $\begin{array}{l}-0.77 \\
.20\end{array}$ & $\begin{array}{l}+2.53 \\
1.98\end{array}$ \\
\hline $\begin{array}{l}\text { Mean Length of } \\
\text { Utterance in } \\
\text { Morphemes (MLU }\end{array}$ & $\begin{array}{l}6.22 \\
.32 \\
J\end{array}$ & $\begin{array}{c}5.54 \\
.44\end{array}$ & $\begin{array}{c}6.12 \\
.79\end{array}$ & $\begin{array}{c}8.39 \\
.53\end{array}$ & $\begin{array}{c}5.83 \\
.57\end{array}$ & $\begin{array}{c}8.78 \\
.39\end{array}$ & $\begin{array}{r}4.79 \\
1.20\end{array}$ & $\begin{array}{c}5.80 \\
.91\end{array}$ & $\begin{array}{l}4.80 \\
.73\end{array}$ & $\begin{array}{c}8.64 \\
.69\end{array}$ \\
\hline Z-MLU & $-\ldots$ & $\begin{array}{l}-0.34 \\
.22\end{array}$ & $\begin{array}{l}-0.05 \\
.40\end{array}$ & -- & $\begin{array}{c}-1.40 \\
.31\end{array}$ & $\begin{array}{l}+0.21 \\
.21\end{array}$ & $\begin{array}{l}-1.97 \\
.66\end{array}$ & $\begin{array}{c}-1.42 \\
.50\end{array}$ & $\begin{array}{c}-1.96 \\
.40\end{array}$ & $\begin{array}{l}+0.13 \\
.38\end{array}$ \\
\hline \# Propositions & $\begin{array}{l}59.1 \\
4.6\end{array}$ & $\begin{array}{l}47.1 \\
5.2\end{array}$ & $\begin{array}{l}56.4 \\
11.2\end{array}$ & $\begin{array}{l}69.6 \\
9.0\end{array}$ & $\begin{array}{l}53.6 \\
8.8\end{array}$ & $\begin{array}{l}125.3 \\
6.4\end{array}$ & $\begin{array}{l}32.0 \\
9.3\end{array}$ & $\begin{array}{l}71.0 \\
15.0\end{array}$ & $\begin{array}{l}36.4 \\
8.7\end{array}$ & $\begin{array}{l}86.3 \\
25\end{array}$ \\
\hline Z-Propositions & $-\ldots$ & $\begin{array}{l}-.42 \\
.18\end{array}$ & $\begin{array}{l}-.09 \\
.39\end{array}$ & -- & $\begin{array}{l}-.51 \\
.28\end{array}$ & $\begin{array}{l}1.79 \\
.20\end{array}$ & $\begin{array}{l}-1.21 \\
.30\end{array}$ & $\begin{array}{l}.05 \\
.48\end{array}$ & $\begin{array}{l}-1.06 \\
.28\end{array}$ & $\begin{array}{l}.54 \\
.80\end{array}$ \\
\hline $\begin{array}{l}\text { Propositions/ } \\
\text { Utterance }\end{array}$ & $\begin{array}{l}.98 \\
.06\end{array}$ & $\begin{array}{l}.93 \\
.08\end{array}$ & $\begin{array}{l}1.04 \\
.11\end{array}$ & $\begin{array}{l}1.14 \\
.08\end{array}$ & $\begin{array}{l}.70 \\
.08\end{array}$ & $\begin{array}{l}1.25 \\
.06\end{array}$ & $\begin{array}{l}.56 \\
.26\end{array}$ & $\begin{array}{l}.77 \\
.14\end{array}$ & $\begin{array}{l}.59 \\
.12\end{array}$ & $\begin{array}{l}.96 \\
.16\end{array}$ \\
\hline $\begin{array}{l}\text { Z-Propositions/ } \\
\text { Utterance }\end{array}$ & $-\ldots$ & $\begin{array}{l}-0.14 \\
.23\end{array}$ & $\begin{array}{l}0.09 \\
.33\end{array}$ & $-\ldots$ & $\begin{array}{l}-1.52 \\
.29\end{array}$ & $\begin{array}{l}0.37 \\
.21\end{array}$ & $\begin{array}{l}-2.01 \\
.88\end{array}$ & $\begin{array}{l}-1.28 \\
.50\end{array}$ & $\begin{array}{l}-1.89 \\
.42\end{array}$ & $\begin{array}{l}-0.63 \\
.57\end{array}$ \\
\hline \#Complex Sents. & $\begin{array}{l}15.84 \\
1.50\end{array}$ & $\begin{array}{l}11.58 \\
1.65\end{array}$ & $\begin{array}{l}14.64 \\
3.60\end{array}$ & $\begin{array}{l}17.58 \\
2.76\end{array}$ & $\begin{array}{l}13.36 \\
3.19\end{array}$ & $\begin{array}{l}35.57 \\
3.73\end{array}$ & $\begin{array}{l}5.67 \\
4.7\end{array}$ & $\begin{array}{l}16.33 \\
4.91\end{array}$ & $\begin{array}{l}8.00 \\
3.45\end{array}$ & $\begin{array}{l}27.00 \\
8.50\end{array}$ \\
\hline Z-Complex Sents. & $-\ldots$ & $\begin{array}{c}-.46 \\
.18\end{array}$ & $\begin{array}{r}-.13 \\
.39\end{array}$ & - & $\begin{array}{l}-.44 \\
.33\end{array}$ & $\begin{array}{l}2.09 \\
.39\end{array}$ & $\begin{array}{l}-1.24 \\
.49\end{array}$ & $\begin{array}{l}-.13 \\
.51\end{array}$ & $\begin{array}{l}-1.00 \\
.36\end{array}$ & $\begin{array}{l}.98 \\
.89\end{array}$ \\
\hline $\begin{array}{l}\text { Complex Sents/ } \\
\text { Utterance }\end{array}$ & $\begin{array}{l}.26 \\
.02\end{array}$ & $\begin{array}{l}.22 \\
.02\end{array}$ & $\begin{array}{r}.26 \\
.04\end{array}$ & $\begin{array}{l}.28 \\
.025\end{array}$ & $\begin{array}{l}.174 \\
.04\end{array}$ & $\begin{array}{r}.37 \\
.04\end{array}$ & $\begin{array}{r}.12 \\
.11\end{array}$ & $\begin{array}{l}.176 \\
.05\end{array}$ & $\begin{array}{r}.13 \\
.05\end{array}$ & $\begin{array}{l}.30 \\
.06\end{array}$ \\
\hline $\begin{array}{l}\text { Z-Complex Sent./ } \\
\text { Utterance }\end{array}$ & $-\ldots$ & $\begin{array}{r}-.32 \\
.21\end{array}$ & $\begin{array}{c}-.03 \\
.37\end{array}$ & $-\ldots$ & $\begin{array}{c}-1.25 \\
.41\end{array}$ & $\begin{array}{c}1.05 \\
.44\end{array}$ & $\begin{array}{c}-1.87 \\
1.27\end{array}$ & -1.23 & $\begin{array}{c}-1.80 \\
.60\end{array}$ & $\begin{array}{r}.24 \\
.72\end{array}$ \\
\hline
\end{tabular}


TABLE 3: DESCRIPTIVE STATISTICS FOR CHILD \& ADULT PATIENTS AND AGE-MATCHED CONTROLS (means, with standard errors below)

\begin{tabular}{|c|c|c|c|c|c|c|c|c|c|c|}
\hline & $\begin{array}{l}\text { Child } \\
\text { Normal } \\
\mathbf{n}=\mathbf{3 8}\end{array}$ & $\begin{array}{l}\text { Child } \\
\text { LHD } \\
n=24\end{array}$ & $\begin{array}{l}\text { Child } \\
\text { RHD } \\
n=14\end{array}$ & $\begin{array}{l}\text { Adult } \\
\text { Normal } \\
n=12\end{array}$ & $\begin{array}{l}\text { Adult } \\
\text { LHD } \\
n=14\end{array}$ & $\begin{array}{l}\text { Adult } \\
\text { RHD } \\
\mathbf{n}=7\end{array}$ & $\begin{array}{c}\text { Broca's } \\
\text { Aphasic } \\
n=3\end{array}$ & $\begin{array}{l}\text { Wernicke's } \\
\text { Aphasic } \\
\mathbf{n}=\mathbf{3}\end{array}$ & $\begin{array}{c}\text { Anomic } \\
\text { Aphasic } \\
n=5\end{array}$ & $\begin{array}{l}\text { Non-Aphasic } \\
\text { LHD } \\
\mathbf{n}=\mathbf{3}\end{array}$ \\
\hline \# Complex Types & $\begin{array}{l}6.66 \\
.39\end{array}$ & $\begin{array}{l}5.13 \\
.51\end{array}$ & $\begin{array}{l}6.07 \\
.92\end{array}$ & $\begin{array}{l}8.08 \\
.73\end{array}$ & $\begin{array}{l}6.07 \\
1.02\end{array}$ & $\begin{array}{l}10.71 \\
.47\end{array}$ & $\begin{array}{l}3.33 \\
2.4\end{array}$ & $\begin{array}{l}8.33 \\
.33\end{array}$ & $\begin{array}{l}4.00 \\
1.14\end{array}$ & $\begin{array}{l}10.00 \\
2.00\end{array}$ \\
\hline Z-Complex Types & $-\ldots$ & $\begin{array}{l}-.63 \\
.21\end{array}$ & $\begin{array}{l}-.24 \\
.38\end{array}$ & $\ldots$ & $\begin{array}{l}-.79 \\
.40\end{array}$ & $\begin{array}{l}1.04 \\
.19\end{array}$ & $\begin{array}{l}-1.87 \\
.95\end{array}$ & $\begin{array}{l}.10 \\
.13\end{array}$ & $\begin{array}{l}-1.60 \\
.45\end{array}$ & $\begin{array}{l}.76 \\
.79\end{array}$ \\
\hline $\begin{array}{l}\text { Complex Types/ } \\
\text { Utterance }\end{array}$ & $\begin{array}{l}.115 \\
.007\end{array}$ & $\begin{array}{l}.11 \\
.01\end{array}$ & $\begin{array}{l}.12 \\
.01\end{array}$ & $\begin{array}{l}.14 \\
.01\end{array}$ & $\begin{array}{l}.08 \\
.01\end{array}$ & $\begin{array}{l}.107 \\
.005\end{array}$ & $\begin{array}{l}.067 \\
.058\end{array}$ & $\begin{array}{l}.09 \\
.009\end{array}$ & $\begin{array}{l}.064 \\
.016\end{array}$ & $\begin{array}{r}.11 \\
006\end{array}$ \\
\hline $\begin{array}{l}\text { Z-Complex Types/ } \\
\text { Utterance }\end{array}$ & $-\ldots$ & $\begin{array}{l}-0.09 \\
.30\end{array}$ & $\begin{array}{l}0.12 \\
.35\end{array}$ & $-\ldots$ & $\begin{array}{l}-1.78 \\
.38\end{array}$ & $\begin{array}{l}-1.03 \\
.16\end{array}$ & $\begin{array}{l}-2.20 \\
1.69\end{array}$ & $\begin{array}{l}-1.49 \\
.25\end{array}$ & $\begin{array}{l}-2.29 \\
.46\end{array}$ & $\begin{array}{c}-0.81 \\
.16\end{array}$ \\
\hline $\begin{array}{l}\text { Fragments/ } \\
\text { All Sentences }\end{array}$ & $\begin{array}{l}.415 \\
.023\end{array}$ & $\begin{array}{l}.44 \\
.03\end{array}$ & $\begin{array}{l}.36 \\
.05\end{array}$ & $\begin{array}{l}.24 \\
.04\end{array}$ & $\begin{array}{r}.43 \\
.05\end{array}$ & $\begin{array}{l}.175 \\
.02\end{array}$ & $\begin{array}{l}.57 \\
.12\end{array}$ & $\begin{array}{l}.41 \\
.09\end{array}$ & $\begin{array}{l}.45 \\
.07\end{array}$ & $\begin{array}{l}.28 \\
.06\end{array}$ \\
\hline $\begin{array}{l}\text { Z-Fragments/ } \\
\text { All Sentences }\end{array}$ & $-\ldots$ & $\begin{array}{l}0.18 \\
.20\end{array}$ & $\begin{array}{l}-0.36 \\
.34\end{array}$ & $\ldots$ & $\begin{array}{l}1.39 \\
.36\end{array}$ & $\begin{array}{l}-0.53 \\
.12\end{array}$ & $\begin{array}{l}2.44 \\
.95\end{array}$ & $\begin{array}{l}1.24 \\
.67\end{array}$ & $\begin{array}{l}1.56 \\
.56\end{array}$ & $\begin{array}{l}0.24 \\
.49\end{array}$ \\
\hline \# Errors & $\begin{array}{l}6.26 \\
.65\end{array}$ & $\begin{array}{l}7.08 \\
1.24\end{array}$ & $\begin{array}{l}9.21 \\
3.21\end{array}$ & $\begin{array}{l}0.08 \\
.08\end{array}$ & $\begin{array}{l}11.29 \\
2.35\end{array}$ & $\begin{array}{l}2.57 \\
.97\end{array}$ & $\begin{array}{l}22.67 \\
5.61\end{array}$ & $\begin{array}{l}15.33 \\
2.33\end{array}$ & $\begin{array}{l}4.60 \\
1.75\end{array}$ & $\begin{array}{l}7.00 \\
1.0\end{array}$ \\
\hline Z-\# Errors & $-\ldots$ & $\begin{array}{l}0.21 \\
.31\end{array}$ & $\begin{array}{l}0.74 \\
.80\end{array}$ & $\ldots$ & $\begin{array}{l}38.76 \\
8.13\end{array}$ & $\begin{array}{l}8.61 \\
3.37\end{array}$ & $\begin{array}{l}78.14 \\
19.40\end{array}$ & $\begin{array}{l}52.77 \\
8.07\end{array}$ & $\begin{array}{l}15.63 \\
6.05\end{array}$ & $\begin{array}{l}23.93 \\
3.46\end{array}$ \\
\hline $\begin{array}{l}\text { Errors/ } \\
\text { Proposition }\end{array}$ & $\begin{array}{l}.12 \\
.012\end{array}$ & $\begin{array}{l}.16 \\
.025\end{array}$ & $\begin{array}{l}.174 \\
.04\end{array}$ & $\begin{array}{l}.002 \\
, 002\end{array}$ & $\begin{array}{l}.34 \\
.14\end{array}$ & $\begin{array}{l}.02 \\
.008\end{array}$ & $\begin{array}{l}1.02 \\
.54\end{array}$ & $\begin{array}{l}.25 \\
.09\end{array}$ & $\begin{array}{l}.14 \\
.052\end{array}$ & $\begin{array}{l}.09 \\
.019\end{array}$ \\
\hline Z-Errors/ & -- & 0.56 & 0.76 & $-\ldots$ & 68.33 & 3.71 & 203.40 & 49.99 & 28.48 & 18.00 \\
\hline Proposition & & .34 & .52 & & 28.33 & 1.64 & 108.36 & 18.56 & 10.49 & 3.78 \\
\hline \# Morph. Errors & $\begin{array}{l}2.26 \\
.25\end{array}$ & $\begin{array}{l}2.46 \\
.60\end{array}$ & $\begin{array}{l}3.71 \\
1.84\end{array}$ & $\begin{array}{l}0.08 \\
.08\end{array}$ & $\begin{array}{l}1.57 \\
.49\end{array}$ & $\begin{array}{l}1.00 \\
.38\end{array}$ & $\begin{array}{l}3.33 \\
1.33\end{array}$ & $\begin{array}{l}\mathbf{0 . 3 3} \\
.33\end{array}$ & $\begin{array}{l}.60 \\
.24\end{array}$ & $\begin{array}{l}2.67 \\
1.20\end{array}$ \\
\hline
\end{tabular}


TABLE 3: DESCRIPTIVE STATISTICS FOR CHILD \& ADULT PATIENTS AND AGE-MATCHED CONTROLS (means, with standard errors below)

\begin{tabular}{|c|c|c|c|c|c|c|c|c|c|c|}
\hline & $\begin{array}{l}\text { Child } \\
\text { Normal } \\
\mathbf{n}=\mathbf{3 8}\end{array}$ & $\begin{array}{l}\text { Child } \\
\text { LHD } \\
\text { n }=24\end{array}$ & $\begin{array}{l}\text { Child } \\
\text { RHD } \\
\text { n }=14\end{array}$ & $\begin{array}{l}\text { Adult } \\
\text { Normal } \\
n=12\end{array}$ & $\begin{array}{l}\text { Adult } \\
\text { LHD } \\
n=14\end{array}$ & $\begin{array}{l}\text { Adult } \\
\text { RHD } \\
n=7\end{array}$ & $\begin{array}{c}\text { Broca's } \\
\text { Aphasic } \\
n=3\end{array}$ & $\begin{array}{l}\text { Wernicke's } \\
\text { Aphasic } \\
\mathbf{n}=\mathbf{3}\end{array}$ & $\begin{array}{c}\text { Anomic } \\
\text { Aphasic } \\
n=5\end{array}$ & $\begin{array}{l}\text { Non-Aphasic } \\
\text { LHD } \\
\mathbf{n}=\mathbf{3}\end{array}$ \\
\hline Z-\#Morph Errors & $-\ldots$ & $\begin{array}{l}0.02 \\
.30\end{array}$ & $\begin{array}{l}0.37 \\
.54\end{array}$ & 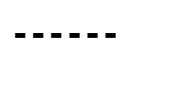 & $\begin{array}{l}7.11 \\
2.35\end{array}$ & $\begin{array}{l}1.19 \\
.62\end{array}$ & $\begin{array}{l}20.92 \\
4.79\end{array}$ & $\begin{array}{l}1.05 \\
1.45\end{array}$ & $\begin{array}{l}3.20 \\
1.81\end{array}$ & $\begin{array}{l}5.86 \\
2.15\end{array}$ \\
\hline $\begin{array}{l}\text { Morph Errors/ } \\
\text { Proposition }\end{array}$ & $\begin{array}{l}.047 \\
.006\end{array}$ & $\begin{array}{l}.046 \\
.012\end{array}$ & $\begin{array}{l}.06 \\
.02\end{array}$ & $\begin{array}{l}.002 \\
.002\end{array}$ & $\begin{array}{l}.038 \\
.01\end{array}$ & $\begin{array}{l}.008 \\
.003\end{array}$ & $\begin{array}{l}.117 \\
.024\end{array}$ & $\begin{array}{l}.007 \\
.007\end{array}$ & $\begin{array}{l}.018 \\
.009\end{array}$ & $\begin{array}{l}.031 \\
.01\end{array}$ \\
\hline $\begin{array}{l}\text { Z/Morph Errors/ } \\
\text { Proposition }\end{array}$ & $-\ldots$ & $\begin{array}{l}-0.018 \\
.30\end{array}$ & $\begin{array}{l}0.37 \\
.54\end{array}$ & $-\ldots$ & $\begin{array}{l}7.11 \\
2.35\end{array}$ & $\begin{array}{l}1.19 \\
.62\end{array}$ & $\begin{array}{l}20.92 \\
4.79\end{array}$ & $\begin{array}{l}1.05 \\
1.45\end{array}$ & $\begin{array}{l}3.20 \\
1.81\end{array}$ & $\begin{array}{l}5.86 \\
2.15\end{array}$ \\
\hline \# Omissions & $\begin{array}{l}2.47 \\
.30\end{array}$ & $\begin{array}{l}3.21 \\
.82\end{array}$ & $\begin{array}{l}3.79 \\
1.11\end{array}$ & $\begin{array}{l}0.00 \\
.00\end{array}$ & $\begin{array}{l}5.36 \\
1.22\end{array}$ & $\begin{array}{l}0.71 \\
.47\end{array}$ & $\begin{array}{l}10.67 \\
2.40\end{array}$ & $\begin{array}{l}8.67 \\
.67\end{array}$ & $\begin{array}{l}1.80 \\
1.11\end{array}$ & $\begin{array}{l}2.67 \\
.88\end{array}$ \\
\hline Z-Omissions & $-\ldots$ & $\begin{array}{l}.40 \\
.44\end{array}$ & $\begin{array}{l}.71 \\
.60\end{array}$ & --- & $-\ldots$ & --- & --- & $-\ldots$ & $-\ldots-$ & --- \\
\hline $\begin{array}{l}\text { Omissions/ } \\
\text { Proposition }\end{array}$ & $\begin{array}{l}.043 \\
.006\end{array}$ & $\begin{array}{l}.081 \\
.018\end{array}$ & $\begin{array}{l}.081 \\
.02\end{array}$ & $\begin{array}{l}.00 \\
.00\end{array}$ & $\begin{array}{l}.153 \\
.06\end{array}$ & $\begin{array}{l}.006 \\
.004\end{array}$ & $\begin{array}{l}.45 \\
.195\end{array}$ & $\begin{array}{l}.13 \\
.022\end{array}$ & $\begin{array}{l}.055 \\
.033\end{array}$ & $\begin{array}{l}.046 \\
.029\end{array}$ \\
\hline $\begin{array}{l}\text { Z-Omissions/ } \\
\text { Proposition }\end{array}$ & $-\ldots$ & $\begin{array}{l}.95 \\
.45\end{array}$ & $\begin{array}{l}.96 \\
.49\end{array}$ & $-\ldots$ & $-\ldots$ & $-\ldots$ & $-\ldots$ & $-\ldots$ & $\ldots$ & $-\ldots$ \\
\hline \#Lexical Errors & $\begin{array}{l}1.03 \\
.18\end{array}$ & $\begin{array}{l}1.17 \\
.22\end{array}$ & $\begin{array}{l}1.43 \\
.39\end{array}$ & $\begin{array}{l}0.00 \\
.00\end{array}$ & $\begin{array}{l}2.79 \\
.64\end{array}$ & $\begin{array}{l}0.86 \\
.26\end{array}$ & $\begin{array}{l}2.67 \\
1.33\end{array}$ & $\begin{array}{l}5.00 \\
1.73\end{array}$ & $\begin{array}{l}2.20 \\
1.02\end{array}$ & $\begin{array}{l}1.67 \\
.88\end{array}$ \\
\hline Z-Lexical Errors & $-\ldots$ & $\begin{array}{l}.12 \\
.20\end{array}$ & $\begin{array}{l}.35 \\
.34\end{array}$ & $-\ldots$ & $-\ldots$ & $-\ldots$ & $-\ldots$ & $-\ldots$ & $-\ldots$ & $-\ldots$ \\
\hline $\begin{array}{l}\text { Lexical Errors/ } \\
\text { Proposition }\end{array}$ & $\begin{array}{l}.015 \\
.003\end{array}$ & $\begin{array}{l}.025 \\
.005\end{array}$ & $\begin{array}{l}.025 \\
.007\end{array}$ & $\begin{array}{l}.00 \\
.00\end{array}$ & $\begin{array}{l}.075 \\
.02\end{array}$ & $\begin{array}{l}.007 \\
.002\end{array}$ & .128 & $\begin{array}{l}.089 \\
.045\end{array}$ & $\begin{array}{l}.071 \\
.039\end{array}$ & $\begin{array}{l}.015 \\
.008\end{array}$ \\
\hline $\begin{array}{l}\text { Z-Lexical Errors/ } \\
\text { Proposition }\end{array}$ & $-\ldots$ & $\begin{array}{l}.52 \\
.27\end{array}$ & $\begin{array}{l}.48 \\
.34\end{array}$ & .... & .... & -... & $-\ldots$ & .... & $-\ldots$ & ---- \\
\hline
\end{tabular}


Table 4: Statistical Results for Amount and Length of Speech

\begin{tabular}{|c|c|c|c|c|c|}
\hline TEST/EFFECT & \# of Utterances & \# of Word Tokens & \# of Word Types & \# \# of Morphemes & \multirow{2}{*}{$\begin{array}{c}\text { MLU in } \\
\text { Morphemes }\end{array}$} \\
\hline & & & & & \\
\hline \multicolumn{6}{|l|}{ Age $x$ Lesion Anova: } \\
\hline Age - F(1,108) & $28.08, p<.0001$ & $29.44, \mathrm{p}<.0001$ & 48.74, p $<.0001$ & 31.85, p $<.0001$ & $11.92, p<.001$ \\
\hline Lesion - F(2,108) & $2.31, \mathrm{p}<.11$ & $3.45, \mathrm{p}<.035$ & $5.12, p<.008$ & $4.13, p<.02$ & $4.78, p<.01$ \\
\hline Age $x$ Lesion $F(2,108)$ & $9.88, p<.0001$ & $6.61, p<.002$ & $9.76, p<.0001$ & $7.81, p<.001$ & $2.60, p<.08$ \\
\hline \multicolumn{6}{|l|}{ One-Way Lesion Anovas: } \\
\hline Adults: $F(2,32)$ & $5.08, p<.013$ & $3.78, \mathrm{p}<.034$ & $5.60, p<.009$ & $4.48, p<.02$ & 8.72, p $<.001$ \\
\hline Children: $F(2,75)$ & $<1$, n.s. & 1.14, n.s. & $3.48, \mathrm{p}<.036$ & 1.49, n.s. & $<1$, n.s. \\
\hline \multicolumn{6}{|l|}{ Paired Comparisons: Adults } \\
\hline LHD vs. RHD - t(19) & $-1.72, p<.11$ & $-2.05, p<.054$ & $-2.83, p<.011$ & $-2.27, p<.035$ & $-3.42, p<.003$ \\
\hline LHD vs. Normal - t(24) & $-1.51, p<.15$ & $<1$, n.s. & $<1$, n.s. & $<1$, n.s. & $3.25, p<.003$ \\
\hline RHD vs. Normal - t(17) & $-4.07, p<.001$ & $-3.37, p<.004$ & $-3.65, p<.002$ & $-3.59, p<.002$ & $<1$, n.s. \\
\hline \multicolumn{6}{|l|}{ Paired Comparisons: Child } \\
\hline LHD vs. RHD - t(36) & $<1$, n.s. & $<1$, n.s. & $<1$, n.s. & $<1$, n.s. & $<1$, n.s. \\
\hline LHD vs. Normal - t(60) & 1.26, n.s. & $1.69, p<.10$ & $2.66, p<.01$ & $1.92, p<.06$ & 1.27, n.s. \\
\hline RHD vs. Normal - t(50) & 1.02, n.s. & $<1$, n.s. & $1.44, p<.16$ & $<1$, n.s. & $<1$, n.s. \\
\hline \multicolumn{6}{|l|}{ Adult/Child Comparisons } \\
\hline Normals - t(48) & 1, n.S.. & $-2.32, p<.025$ & $-3.39, p<.001$ & $-2.44, p<.018$ & $-3.42, p<.001$ \\
\hline LHD - t(36) & $-2.96, p<.005$ & $-2.37, p<.023$ & $-2.70, p<.011$ & $-2.38, p<.023$ & $<1$, n.s. \\
\hline RHD - t(19) & $-5.61, p<.0001$ & $-5.13, p<.0001$ & $-7.19, p<.0001$ & $-5.33, p<.0001$ & $-2.29, p<.034$ \\
\hline z-score LHD - t(36) & $-2.42, p<.0001$ & $-1.44, p<.16$ & -1.22, n.S. & $-1.42, p<.17$ & $-2.78, p<.009$ \\
\hline z-score RHD - t(19) & $-4.24, p<.0001$ & $-2.81, p<.011$ & $-4.16, p<.001$ & $-3.23, p<.004$ & $<1$, n.s. \\
\hline
\end{tabular}


Table 5: Statistical Results for Analyses of Complexity

\begin{tabular}{|c|c|c|c|c|}
\hline TEST/EFFECT & $\begin{array}{c}\text { Propositions per } \\
\text { Utterance }\end{array}$ & $\begin{array}{c}\text { Complex Tokens } \\
\text { per Utterance }\end{array}$ & $\begin{array}{c}\text { Complex Types } \\
\text { per Utterance }\end{array}$ & \multirow{2}{*}{$\begin{array}{c}\text { Fragments per All } \\
\text { Sentences } \\
\text { Produced } \\
\end{array}$} \\
\hline \multirow{2}{*}{\multicolumn{5}{|c|}{ Age $x$ Lesion Anova: }} \\
\hline & & & & \\
\hline Age - F(1,108) & $<1$, n.s. & $<1$, n.s. & $<1$, n.s. & $13.35, p<.0001$ \\
\hline Lesion - F(2,108) & $4.16, p<.018$ & $4.54, p<.013$ & $2.11, p<.13$ & $6.62, \mathrm{p}<.002$ \\
\hline Age $x$ Lesion $F(2,108)$ & $3.98, \mathrm{p}<.022$ & $2.84, p<.063$ & $3.28, \mathrm{p}<.041$ & $3.51, \mathrm{p}<.034$ \\
\hline \multicolumn{5}{|l|}{$\begin{array}{c}\text { One-Way Lesion } \\
\text { Anovas: }\end{array}$} \\
\hline Adults: $\quad F(2,32)$ & $11.98, \mathrm{p}<.0001$ & $7.98, \mathrm{p}<.002$ & $7.81, \mathrm{p}<.002$ & $9.26, \mathrm{p}<.001$ \\
\hline Children: $\mathbf{F}(2,75)$ & $<1$, n.s. & $<1$, n.s. & $<1$, n.s. & 1.19, n.s. \\
\hline \multicolumn{5}{|l|}{$\begin{array}{c}\text { Paired Comparisons: } \\
\text { Adults }\end{array}$} \\
\hline LHD vs. RHD - t(19) & $-4.26, p<.0001$ & $-3.48, p<.003$ & -1.33, n.s. & $3.70, \mathrm{p}<.002$ \\
\hline LHD vs. Normal - t(24) & $3.68, p<.001$ & $2.41, \mathrm{p}<.024$ & $3.58, \mathrm{p}<.002$ & $-2.96, p<.007$ \\
\hline RHD vs. Normal - t(17) & $<1$, n.s. & $-2.09, p<.052$ & $2.56, \mathrm{p}<.02$ & $1.35, \mathrm{p}<.20$ \\
\hline \multicolumn{5}{|l|}{$\begin{array}{ll}\text { Paired } & \begin{array}{l}\text { Comparisons: } \\
\text { Child }\end{array}\end{array}$} \\
\hline LHD vs. RHD - t(36) & $<1$, n.s. & $<1$, n.s. & $<1$, n.s. & 1.48. $p<.15$ \\
\hline LHD vs. Normal - t(60) & $<1$, n.s. & 1.22, n.s. & $<1$, n.s. & $<1$, n.s. \\
\hline RHD vs. Normal - t(50) & $<1$, n.s. & $<1$, n.s. & $<1$, n.s. & 1.02, n.s. \\
\hline \multicolumn{5}{|l|}{$\begin{array}{l}\text { Adult/Child } \\
\text { Comparisons }\end{array}$} \\
\hline Normals - t(48) & $-1.46, p<.16$ & $<1$, n.s. & $-1 . .98, p<.054$ & $3.70, \mathrm{p}<.001$ \\
\hline LHD - t(36) & $1.93, p<.062$ & 1.16, n.s. & $1.58, \mathrm{p}<.13$ & $<1$, n.s. \\
\hline RHD - t(19) & $-1.41, p<.18$ & $-1.73, p<.10$ & $<1$, n.s. & $-2.74, p<.013$ \\
\hline z-score LHD - t $(36)$ & $3.71, \mathrm{p}<.001$ & $2.26, \mathrm{p}<.03$ & $3.45, \mathrm{p}<.001$ & $-3.23, p<.003$ \\
\hline z-score RHD - t(19) & $<1$, n.s. & $-1.76, p<.10$ & $2.26, \mathrm{p}<.036$ & $<$ 1, n.s. \\
\hline
\end{tabular}


Table 6: Statistical Results for Error Analyses

\begin{tabular}{|c|c|c|c|c|}
\hline$\overline{\text { TEST/EFFECT }}$ & $\begin{array}{c}\text { Total Errors per } \\
\text { Proposition }\end{array}$ & $\begin{array}{l}\text { Omission Errors } \\
\text { per Proposition* }\end{array}$ & \begin{tabular}{|c|} 
Morph. Errors per \\
Proposition
\end{tabular} & \begin{tabular}{|c|} 
Lexical Errors per \\
Proposition*
\end{tabular} \\
\hline \multicolumn{5}{|l|}{ Age $x$ Lesion Anova: } \\
\hline Age - F(1,108) & $<1$, n.s. & $<1$, n.s. & $10.66, p<.001$ & 1.57, n.s. \\
\hline Lesion - F(2,108) & 4.79, $p<.01$ & $7.04, p<.001$ & $<1$, n.s. & $8.18, p<.001$ \\
\hline Age $x$ Lesion $F(2,108)$ & $6.15, \mathrm{p}<.003$ & 5.16, p $<.007$ & $1.86, p<.16$ & $9.13, p<.0001$ \\
\hline \multicolumn{5}{|l|}{$\begin{array}{c}\text { One-Way Lesion } \\
\text { Anovas: }\end{array}$} \\
\hline Adults: $F(2,32)$ & $3.72, \mathrm{p}<.036$ & $4.60, p<.018$ & $5.38, p<.01$ & $6.51, p<.004$ \\
\hline Children: $F(2,75)$ & $1.91, \mathrm{p}<.16$ & 3.39, p $<.04$ & $<1$, n.s. & $1.91, \mathrm{p}<.16$ \\
\hline \multicolumn{5}{|l|}{$\begin{array}{c}\text { Paired Comparisons: } \\
\text { Adults }\end{array}$} \\
\hline LHD vs. RHD - t(19) & $1.59, \mathrm{p}<.13$ & $1.79, p<.09$ & $1.74, p<.10$ & 2.06, p $<.054$ \\
\hline LHD vs. Normal - t(24) & $-2.23, p<.035$ & $-2.47, p<.021$ & $-2.80, p<.01$ & $-2.89, p<.006$ \\
\hline RHD vs. Normal - t(17) & $-2.93, p<.009$ & $-1.88, p<.08$ & $-2.04, p<.06$ & $-4.81, p<.0001$ \\
\hline \multicolumn{5}{|l|}{$\begin{array}{ll}\text { Paired } & \begin{array}{l}\text { Comparisons: } \\
\text { Child }\end{array}\end{array}$} \\
\hline LHD vs. RHD - t(36) & $<1$, n.s.. & $<1$, n.s. & $<1$, n.s. & $<1$, n.s. \\
\hline LHD vs. Normal - t(60) & $-1.64, p<.11$ & $-2.37, p<.021$ & $<1$, n.s. & $-1.85, p<.07$ \\
\hline RHD vs. Normal - t(50) & $-1.84, p<.08$ & $-2.53, p<.014$ & $<1$, n.s. & $-1.53, p<.14$ \\
\hline \multicolumn{5}{|l|}{$\begin{array}{l}\text { Adult/Child } \\
\text { Comparisons }\end{array}$} \\
\hline Normals - t(48) & 5.46, p $<.0001$ & $4.22, \quad p \quad<.0001$ & $4.02, p<.0001$ & $3.30, \mathrm{p}<.002$ \\
\hline LHD - t(36) & $-1.65 p<.11$ & $-1.46, p<.16$ & $<1$, n.s. & $-2.62 p<.013$ \\
\hline RHD - t(19) & $2.79, \mathrm{p}<.012$ & $2.69, p<.015$ & $1.79, p<.09$ & $1.84, p<.09$ \\
\hline z-score LHD - t(36) & $-3.16, p<.003$ & not applicable & $-3.91, p<.0001$ & not applicable \\
\hline z-score RHD - t(19) & $-2.18, p<.042$ & not applicable & $<1$, n.s. & not applicable \\
\hline
\end{tabular}

